\title{
Nanomaterials: Science and Applications in the Lithium-Sulfur Battery
}

Lin $\mathrm{Ma}^{\mathrm{b}}$, Kenville E. Hendrickson ${ }^{\mathrm{a}}$, Shuya Wei ${ }^{\mathrm{a}}$, and Lynden A. Archer ${ }^{\mathrm{a}, *}$

Graphical Abstract
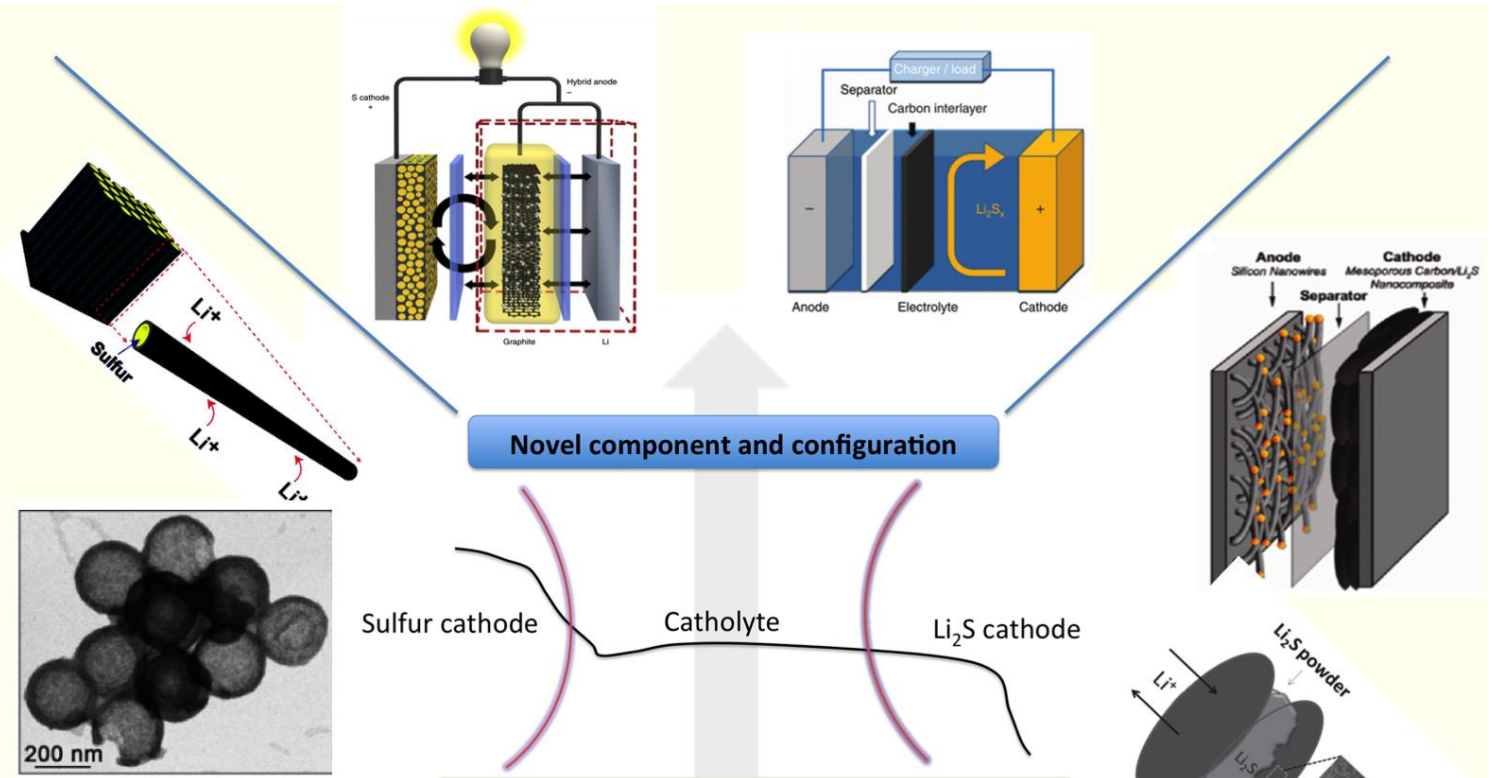

Working mechanism and characterization
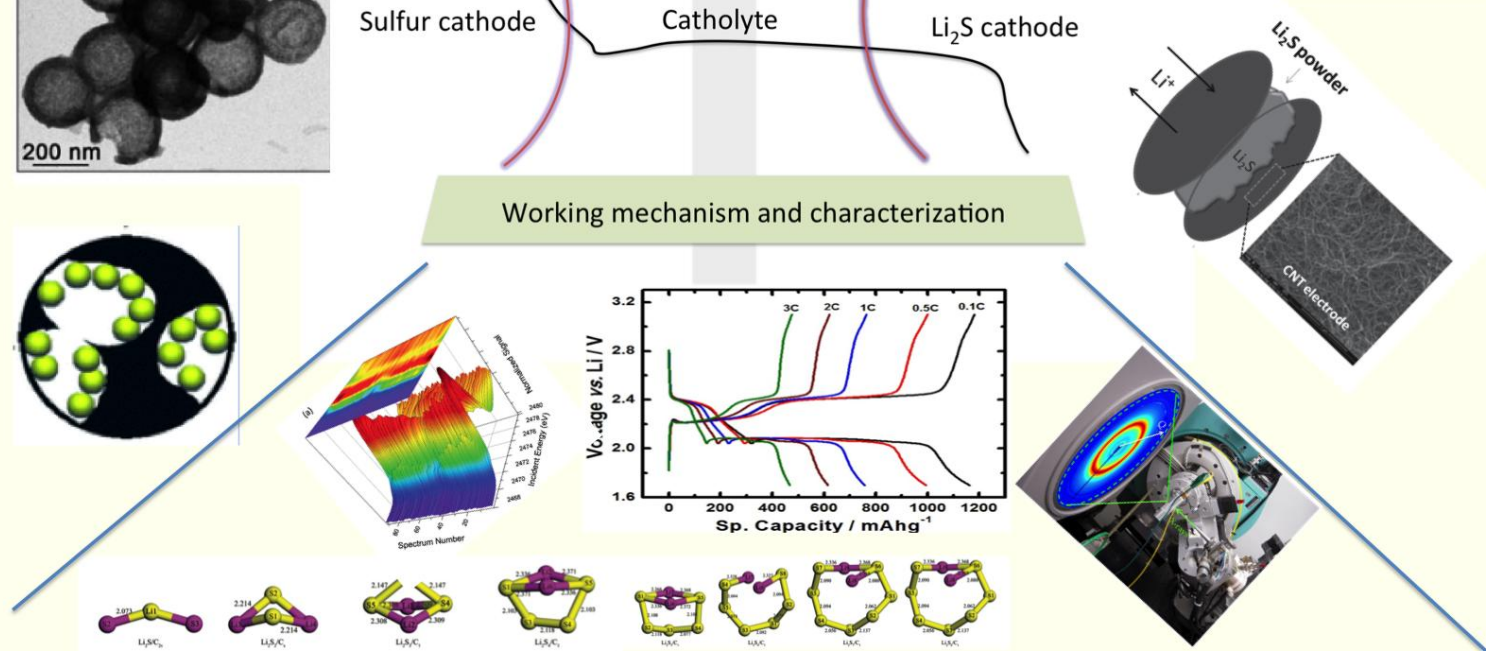


\begin{abstract}
Reliable and cost-effective technologies for electrical energy storage are in great demand in sectors of the global economy ranging from portable devices to transportation to sustainable production of electricity from intermittent sources. Among the various electrochemical energy storage options under consideration, the rechargeable lithiumsulfur (Li-S) battery stands out as among the most promising platforms for reversibly storing large amounts of electrical energy at moderate cost set by the inherent cell chemistry. The success of Li-S storage technology in living up to this promise calls for solutions to fundamental problems associated with the inherently low electrical conductivity of sulfur and sulfides, and the complex solution chemistry of lithiated sulfur compounds in commonly used electrolytes. These problems appear well posed for innovative solutions using nanomaterials and for fundamental answers guided by the tools of nanotechnology. Beginning with a review of current understanding of Li-S battery chemistry and operation, this review discusses how advances in nanocharacterization and theoretical studies of the Li-S system are helping advance understanding of the Li-S battery, in the search for solutions. Factors that prevent Li-S cells from realizing the theoretical capacity set by their chemistry are discussed both in terms of the impressive advances in cell design that have been enabled by application
\end{abstract}


nanomaterials science and in terms of opportunities recent progress in understanding are providing for future work aimed at nanoengineering the cathode and other cell components. Perspectives and directions for future development of the Li-S storage platform are discussed based on accumulated knowledge from previous efforts in the field as well as from the accumulated experience of the writers of this review.

\section{Graphical abstract}

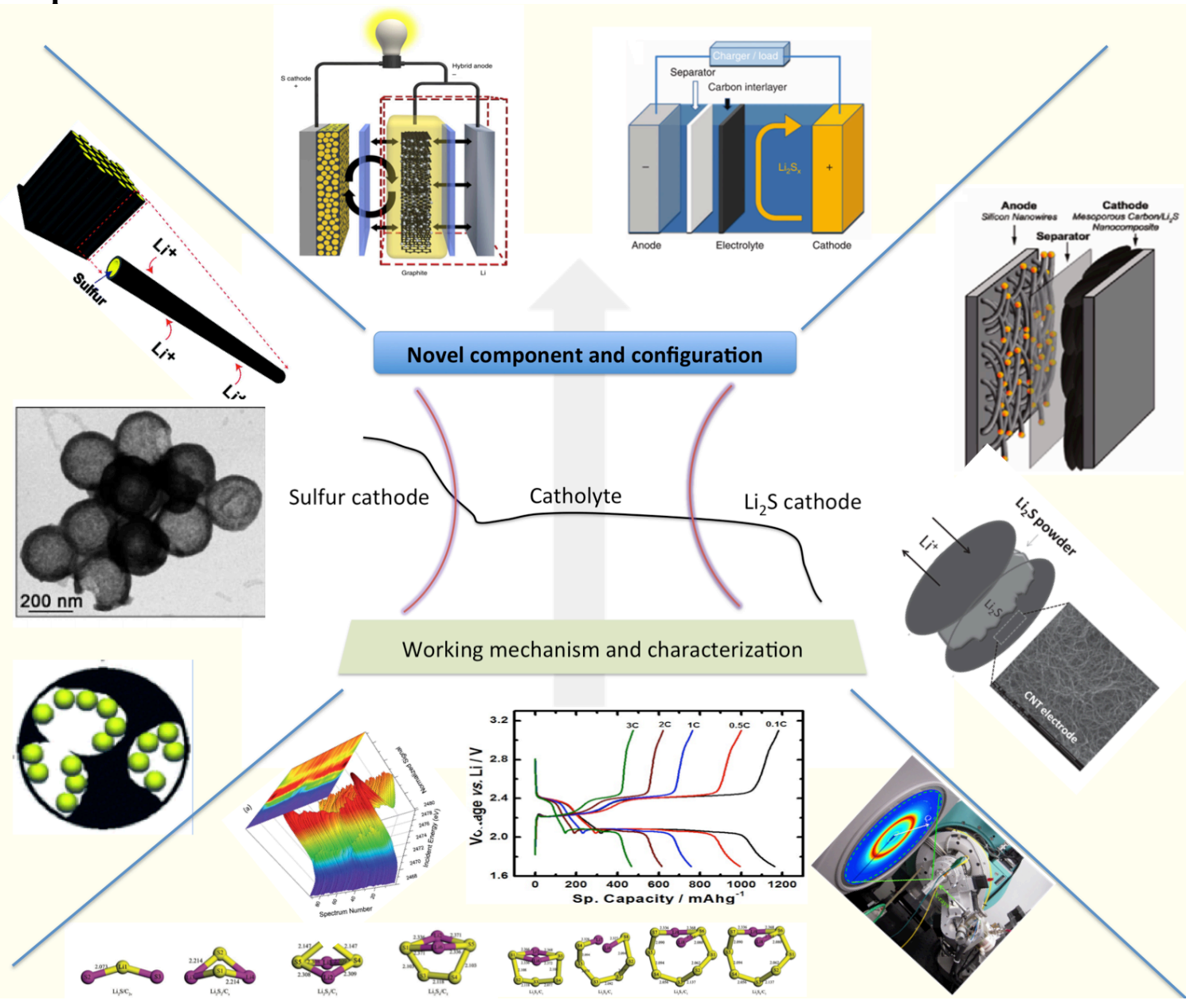

\section{Keywords}

Lithium-Sulfur batteries; Nanomaterials; Sulfur cathodes; Energy storage 


\section{Author's Biographical Sketch}

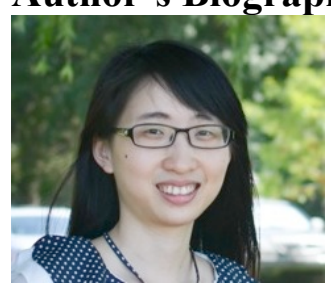

Lin Ma is currently a Ph.D. student in the Department of Materials Science and Engineering at Cornell University since 2012. She received her B.S. in Chemical Engineering from Tsinghua University, China in 2012. Her research focuses on nanomaterials approaches for rational design of metal-sulfur battery cathodes.

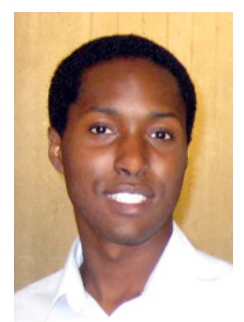

Kenville Hendrickson is a $\mathrm{PhD}$ student in the School of Chemical and Bimolecular Engineering at Cornell University. He received his B.S. in Chemical Engineering from the University of Texas at Austin in 2010 and his M.S. in Chemical Engineering from Cornell University in 2013. His research focuses on solution thermodynamics and transport properties of dissolved polysulfides in lithium-sulfur battery electrolytes.

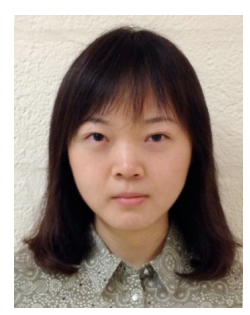

Shuya Wei is a PhD student in the School of Chemical and Bimolecular Engineering at Cornell University. She received her B.Eng. in Bioengineering from Nanyang Technological University, Singapore in 2013. Her research focuses on nanoparticlepolymer composite materials design and their applications in electrochemical enerfy storage technologies.

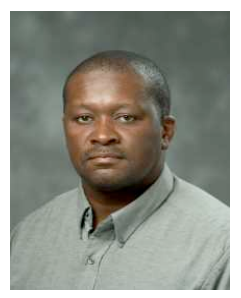

Lynden Archer is the William C. Hooey Director and James A. Friend Family Distinguished Professor of Engineering in the School of Chemical and Biomolecular 
Engineering at Cornell University. Archer's research focuses on transport properties of polymers and polymer-nanoparticle hybrid materials relevant for applications in energy storage technologies. Archer received his Ph.D. in Chemical Engineering from Stanford University in 1994 and was a postdoctoral member of the Technical Staff at AT\&T Bell Laboratories. He is a fellow of the American Physical Society.

\section{Introduction}

Among solid-state cathode materials under consideration for rechargeable lithium batteries, elemental sulfur offers the greatest promise for reversibly storing large amounts of electrical energy at moderate cost. As a cathode, sulfur hosts as many as two lithium ions non-topotactically via the following redox reaction: $16 \mathrm{Li}+\mathrm{S}_{8} \leftrightarrow 8 \mathrm{Li}_{2} \mathrm{~S}$. This reaction is attractive for electrochemical storage for a number of reasons. It can be used to reversibly store large amounts of electrical energy - up to $2500 \mathrm{Wh} / \mathrm{kg}$ or $2800 \mathrm{Wh} / \mathrm{L}$ of sulfur - a factor of ten or more higher than other electrochemical storage technologies (e.g. Ni-H $(80 \mathrm{Wh} / \mathrm{kg}$, $120 \mathrm{Wh} / \mathrm{L})$, Li-ion $(150 \mathrm{Wh} / \mathrm{kg}, 250 \mathrm{Wh} / \mathrm{L})$, and Li-ion polymer batteries $(180 \mathrm{Wh} / \mathrm{kg}, 300 \mathrm{Wh} / \mathrm{L}))$ of contemporary interest (Figure 1). [1-5] The reaction also occurs spontaneously, is fully reversible, and does not require intervention using catalysts or other means. Finally, the reaction can in principle occur entirely in the solid state and generates lithium-sulfur compounds as its only products. This can be contrasted with competing energy storage solutions based on combustion of fossil fuels, which irreversibly generate even larger amounts of energy on a gravimetric or volumetric basis (e.g. commercial coal: $6.7 \mathrm{~kW} \cdot \mathrm{h} / \mathrm{kg}$, and a commercial-grade gasoline: $12 \mathrm{~kW} \cdot \mathrm{h} / \mathrm{kg}, 9 \mathrm{~kW} \cdot \mathrm{h} / \mathrm{L}$ ), but with the added burden of managing harmful $\mathrm{CO}_{2}$ and other gaseous emissions. The low cost of sulfur ( $\$ 0.02 \mathrm{per} g)$ and its availability in regions all over the world provides an additional incentive for development of Lithium-Sulfur (Li-S) electrochemical storage technology $[6,7]$.

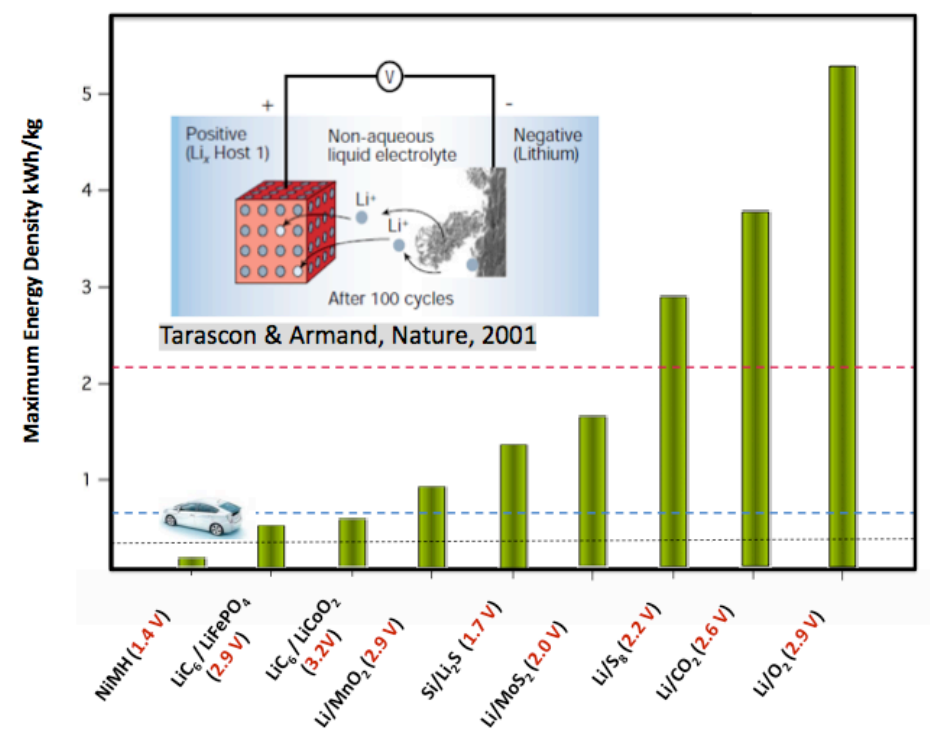

Figure 1. Comparison of the theoretical energy density and discharge voltages of different battery storage platforms. The inset illustrates the challenge with lithium dendrite growth and proliferation that limits adoption of storage technologies to the right of the plow that use metallic lithium as anodes for high overall cell energy densities. The red horizontal line represents the useful energy density of gasoline for transportation (i.e. the energy density of gasoline taking into account the $18 \%$ efficiency of the internal combustion engine). The dashed blue and black lines correspond to the US Advanced battery Consortium (USABC) long-term (2020) and short-term energy density targets, respectively [8]. 
Despite the considerable advantages offered by Li-S storage technology, commercial development of a practical Li-S rechargeable battery has been limited by multiple transport and thermodynamics-related challenges. A goal in writing this review is to show that the most important of these challenges provide opportunities for clever designs of the electrodes and electrolytes for Li-S cells using the toolset of nanomaterials science and engineering. A perhaps more practical motivation for writing the review is that despite the significant advances made over the last decade in improving Li-S battery performance, the actual storage delivered by even the best Li-S cells reported in the literature is still quite far away from the theoretical capacity upon which much of the promise of the Li-S battery lies. The best performing Li-S cells rarely deliver storage capacities above $60 \%$ of the theoretical value for this chemistry. This situation can be contrasted with the state of affairs in more traditional lithium ion batteries, where celllevel performance approaching $90 \%$ of theoretical capacities are common. A Li-S battery that delivers $50 \%$ of its theoretical capacity over hundreds of cycles of charge and discharge already offers superior energy storage to the most energy-dense LIBs on a gravimetric storage basis, but substantially better performance is needed from Li-S cells to compete with LIBs for storage on a volumetric basis. The study carried out by Jie[9] (Figure 2) nicely illustrates this point. The study also underscores the need for Li-S cell designs in which high sulfur loadings in the cathode is achieved. Specifically, at low sulfur loadings, the volumetric energy density for the Li-S battery is noticeably lower than that of commercial lithium ion cells, even if one could realize the theoretical capacity of sulfur. Rechargeable Li-S cells that approach the theoretical capacity of the electrodes at high sulfur loadings are obviously desired.
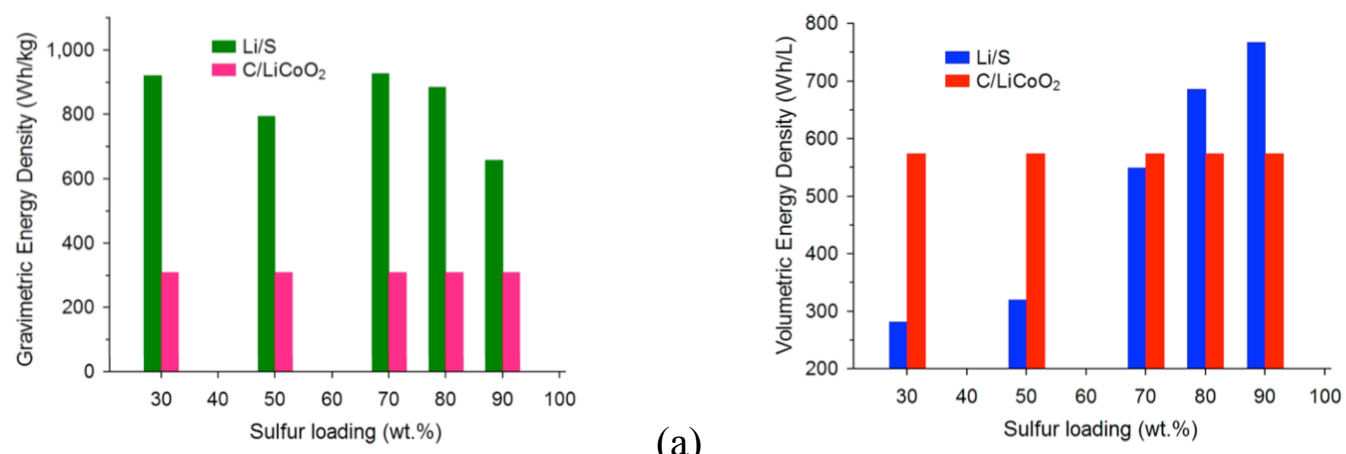

Figure 2. Gravimetric energy densities (a) and Volumetric energy densities (b) of lithium-sulfur cells with different sulfur loading percentages and their comparison to $\mathrm{LiC}_{6} / \mathrm{LiCoO}_{2}$ cell. Reprinted with permission from [9]. Copyrights 2014 American Chemical Society.

In-depth understanding of the working mechanism, transport and other barriers that limit performance of Li-S cells are needed for further progress in the field. Such understanding is also essential to guide emerging efforts aimed at rationally designing each of the components in the Li-S cell towards the goal of full materials utilization. Sulfur is infamous for its poor electrical conductivity $\left(5 \times 10^{-30} \mathrm{~S} / \mathrm{cm}\right.$ at $\left.25^{\circ} \mathrm{C}\right)$ and ease with which it is able to form solid allotropes (over 30 are known) [10]. The first of these traits means that a pure sulfur cathode is intrinsically insulating in nature, which limits the utilization of the active electrode material. High-surface area carbons are typically used as conductive additives within the cathode, but better charge transport in the cell often 
comes at the expense of storage capacity. Additionally, the volume of sulfur increases by around $80 \%$ (density changes from $2.03 \mathrm{~g} / \mathrm{cm}^{3}$ for sulfur to $1.66 \mathrm{~g} / \mathrm{cm}^{3}$ for $\mathrm{Li}_{2} \mathrm{~S}$ ) when it is fully lithiated. This means that synergistic cathode designs that can accommodate the volume change without compromising electronic connections with conductive additives, which do not expand, are critical for stable, long-term cell performance. A consequence of the second trait is that the preferred redox reaction product, $\mathrm{Li}_{2} \mathrm{~S}$, is almost always accompanied by formation of various intermediate lithium polysulfides ( $\mathrm{LiPS}=\mathrm{Li}_{2} \mathrm{~S}_{\mathrm{n}}, 2 \leq$ $\mathrm{n} \leq 8$ ) products (see Figure 3). Depending on the value of $n$, these intermediates can be either insoluble or soluble in the electrolyte, which leads to multiple challenges in managing active materials utilization and reuse. For example, the fully reduced product, $\mathrm{Li}_{2} \mathrm{~S}$ is insoluble in most electrolytes and is both electronically and ionically insulating. Thus, once $\mathrm{Li}_{2} \mathrm{~S}$ begins to form in the sulfur cathode, it can only grow by spreading outwards to cover the exposed surface of the conductive carbon particles in the electrode. Ultimately, this growth produces an insulating film on the carbon, which prevents further electronic and ionic access to the active material in the cathode, and the cell discharge voltage drops rapidly (Figure 4). Especially troublesome, are the soluble $\left(\mathrm{Li}_{2} \mathrm{~S}_{\mathrm{n}}, 2<\mathrm{n}<8\right.$ ) polysulfide discharge products, which establish an internal shuttling pathway between the lithium anode and sulfur cathode that, if unchecked, will continuously consume the active material in both electrodes. Specifically, during the first discharge, the higher order LiPS $(n>2)$ dissolve into the electrolyte, depleting sulfur from the cathode. Once in the electrolyte, polysulfides diffuse freely and ultimately reach the metallic lithium anode where they undergo chemical reaction to form lower order polysulfies, including $\mathrm{Li}_{2} \mathrm{~S}_{\mathrm{n}-1}$ and $\mathrm{Li}_{2} \mathrm{~S}$, which may either deposit on the $\mathrm{Li}$ anode or diffuse back to the sulfur cathode, where they react with sulfur to reform higher-order polysulfides.

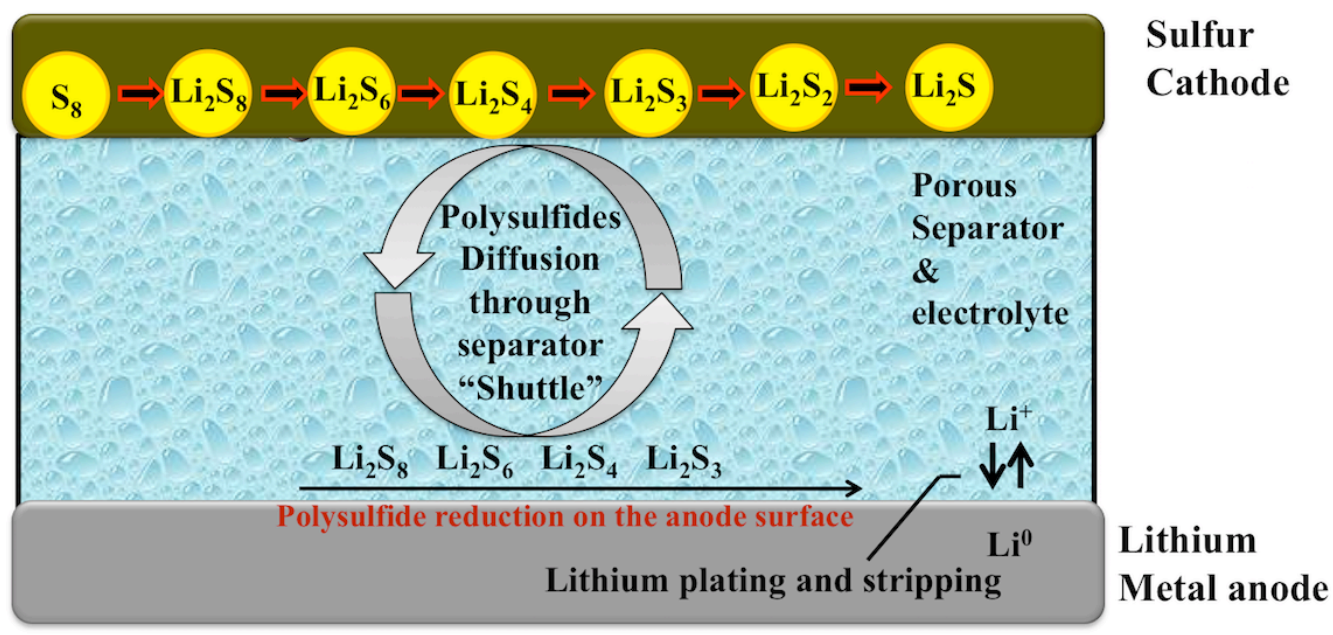

Figure 3. Illustration of polysulfides dissolution and shuttling process in a Li-S battery during the recharge process. Reprinted with permission from [11]. Copyrights 2004 Elsevier.

The parasitic loop or 'shuttle' illustrated in Figure 3 is free to take place repeatedly and continuously during the cell recharge and not only depletes the active electrode materials, but continuously consumes electrical energy from an external circuit. It is easily visualized by the telltale asymmetry in the discharge and charge profiles (Figure 4a) of a Li-S cell and, lowers the Coulombic efficiency of the cell. Shuttling can also occur during 
cell storage and leads to self-discharge, which limits the shelf life of Li-S batteries. Sequestering the sulfur in carbon nanocapsules[12-14] is one of a handful of nanomaterials approaches that have been shown to completely remove this asymmetry (Figure 4a), underscoring its fundamental connection to LiPS dissolution. As illustrated in Figure 4b, without any other intervention strategies, this method completely eliminates the shuttle during the first cycle of charge and discharge for a range of Li-S cell discharge/charge current densities.

In addition to the intrinsically high storage capacity of sulfur, the high overall energy storage capacity of the Li-S cell stems from the use of metallic lithium as the anode. Li is readily ionized in a variety of aprotic liquids and as such provides an efficient complement to sulfur in an electrochemical cell designed to store large amounts of electrical energy. Unfortunately, even at low current densities, Li electrodeposition is sensitive to defects at the electrode surface and is prone to various transport and morphological instabilities $[15,16]$ that lead to growth and proliferation of rough electrodeposits collectively termed dendrites. Nucleated at the anode, these dendrites may grow as mossy deposits that react with the electrolyte and, if unchecked, will ultimately consume it all, drying out the cell. Dendrites may also grow and proliferate in the inter electrode space, ultimately short-circuiting the cell with potentially catastrophic consequences for safety. A remarkable, though poorly studied feature of the Li-S cell is that it possesses multiple internal safety measures that prevent catastrophic failure by dendrite-induced short circuits. LiPS dissolution and shuttling in the electrolyte provides an intrinsic mechanism for passivating dendrite tips by reaction with LiPS species in the electrolyte. Specifically, the tips concentrate electric field lines and the LiPS flux in the electrolyte, which leads to the reduction of LiPS and deposition of insoluble, insulating $\mathrm{Li}_{2} \mathrm{~S}$ on the tip surface limiting/eliminating further deposition of Li. This process also provides a high intrinsic overcharge tolerance for Li-S cells.

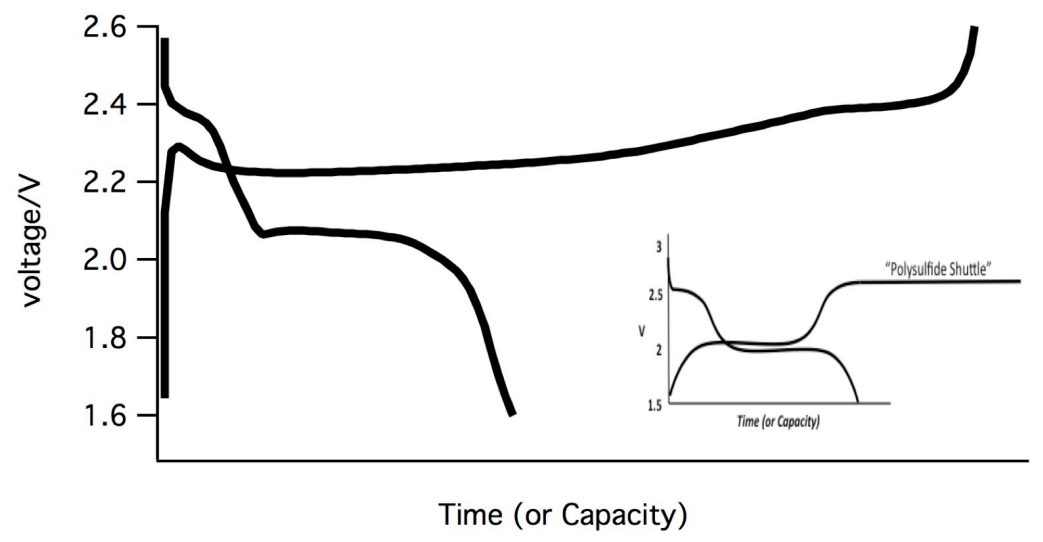

(a) 


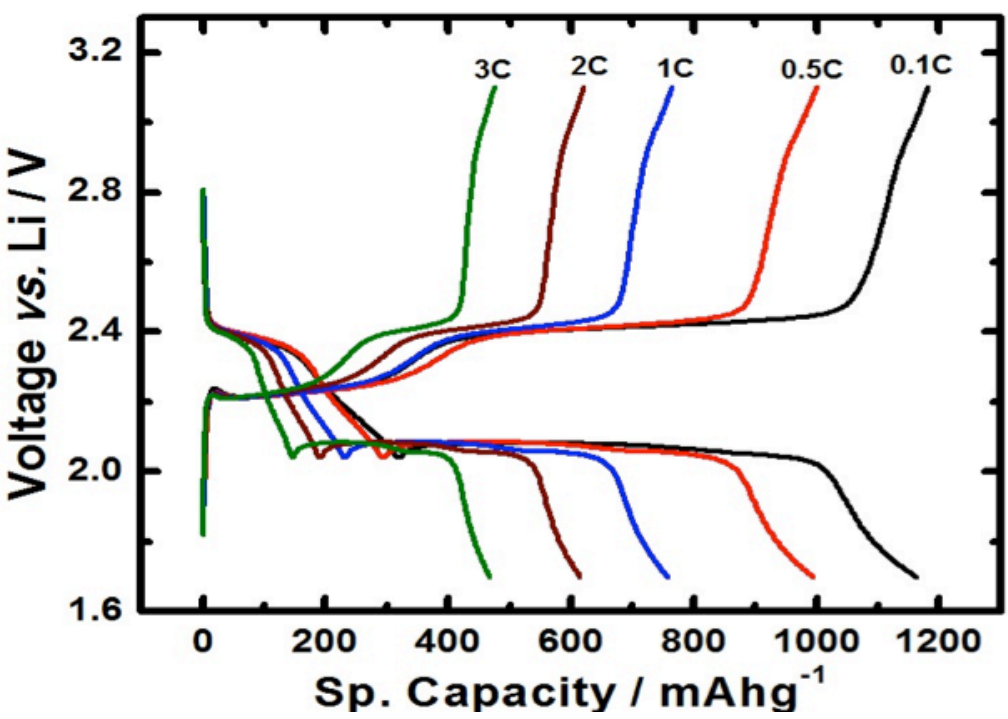

Figure 4. Discharge and Charge Profiles for Li-S cells: (a). Cell in which LiPS shuttling is dominant; inset is the drawing that shows the idea of 'polysulfide shuttling' (b). Cell in which sulfur is sequestered in carbon nanocapsules in which shuttling is eliminated over a wide range of current densities $(0.1-3 \mathrm{C})$. Reprinted with permission from [13]. Copyrights $2011 \mathrm{Wiley-VCH}$ Verlag GmbH \& Co. KGaA, Weinheim.

Through systematic application of nanotechnology to each component of the Li-S cell, significant improvements have been achieved in Li-S battery technology during the last decade. In particular, nanomaterials have been used to address the three most serious shortcomings outlined in the previous section: poor electrical conductivity of sulfur and sulfides; polysulfide-dissolution induced shuttling; and volume expansion. Nanomaterials can provide shorter pathways for ions and electrons, which helps to solve the problem of poor electrical conductivity of the cathode $[4,5]$. The intrinsically high surface-tovolume ratio of nanoparticles based on materials such as carbon with high affinity for sulfur has also been used to advantage to simultaneously provide kinetic barriers to LiPS loss to the electrolyte and to facilitate electronic transport in the cathode. Well-designed nanostructures can also be used as cathode additives to accommodate volume changes during discharge and charge, stabilizing the cathode in order to achieve greater performance.

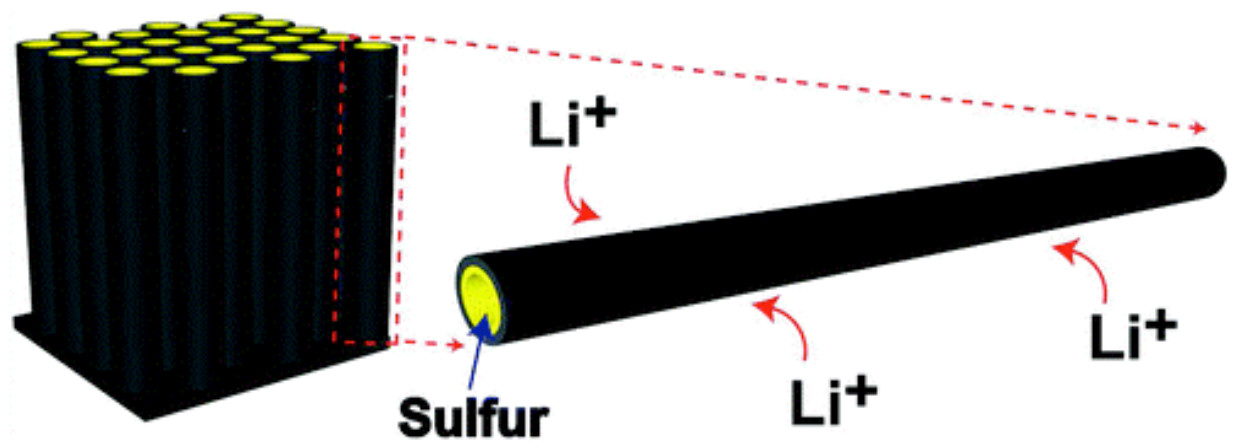


Figure 5. Illustration of nanostructured sulfur-carbon composite cathode; the diameter of the nanotube is $200 \mathrm{~nm}$ and the length is $60 \mu \mathrm{m}$. Reprinted with permission from [17]. Copyright 2011 American Chemical Society.

This effect is underpinned by a fundamental principle applicable to all nanomaterials: if a material of interest is expected to undergo a thermodynamic transition to an unfavorable state with critical nucleation radius $\mathrm{r}_{\mathrm{c}}$, confining the material to a rigid particle of radius $\mathrm{r}_{\mathrm{p}}<\mathrm{r}_{\mathrm{c}}$ eliminate such transitions [18]. Hollow nanostructures with anisotropic shapes (see Figure 5) are particularly advantageous because they can be designed to solve almost all three problems in a sulfur cathode using a single architecture. Specifically, such particles sequester the sulfur on nanometer length scales; they dramatically reduce charge transport distances in the poorly conducting sulfur and sulfide phases contained in the nanometer sized pores; and provide an interconnected network of percolated surface contacts, which at relatively low particle contents, facilitates good electrical connections to an external circuit. An extreme example that illustrates the potential benefits of this strategy is the work by Cui and co-workers[17], which applied a hollow carbon nanofiber-encapsulated sulfur cathode.

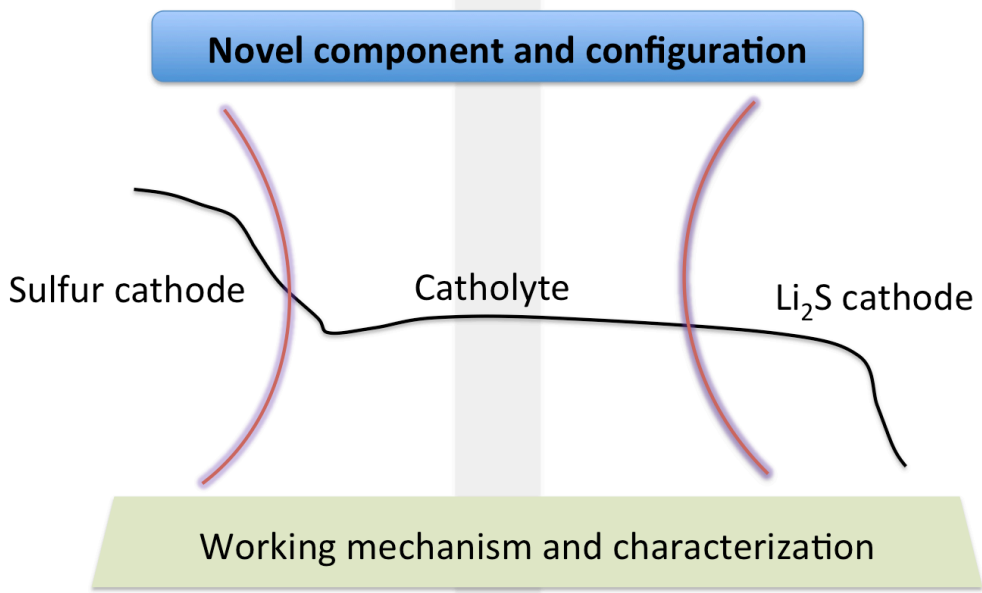

Scheme 1. Organization of the review.

Scheme 1. illustrates the organization of this review. Our goal is to provide a framework for critically assessing progress in Li-S battery technology from a mechanistic standpoint, with the aim of organizing understanding of previous studies and for providing guidance for future work. There are already several excellent reviews that focus on the various methods for enabling Li-S batteries[19-26]. Unfortunately, success is typically measured using coarse-grained applications-focused metrics, such as does the battery cycle better at an acceptable current density, and important details about the reaction mechanisms and of 
how the tools of nanotechnology can be used for characterizing these mechanisms and for diagnosing and remediating underlying electrode failure modes are often neglected. In reality, the Li-S battery literature is much richer and is replete with examples of work that offer deep and clear insights required to create Li-S cells that live up to the theoretical promise of this chemistry.

We begin the review by discussing the growing knowledge of the reaction mechanism of the Li-S cell and by outlining the various characterization techniques used to analyze the sulfur cathode surface. The coverage includes an assessment of theoretical work and of ex-situ and in-situ nano-characterization methods that have been used to understand electrode structure and transport on the nanoscale. Building on this foundation, different nanostructured cathode materials are reviewed and classified: i) Cathodes based on elementary sulfur. The sulfur nanocomposite is classified based on their function in preventing the dissolution and shuttling of polysulfides. A variety of methods have been applied and they can be put into three categories: trapping polysulfides trough physical barrier; sequestering polysulfides by chemical bonding; and the application of multiple functional nanomaterials which combine these two effects. ii) Cathodes based on lithium polysulfides dissolved in electrolyte. By dissolving the lithium polysulfide into the electrolyte one creates a system where the electrolyte and cathode are coupled together and termed a "catholyte" system. iii) Cathodes applying nanostructured $\mathrm{Li}_{2} \mathrm{~S}$. Finally, we will introduce next generation sulfur batteries with novel component and configurations. Researchers have brought up lots of new ideas and nice construction, from which we can propose future direction for durable and high performance Li-S batteries.

\section{Li-S battery fundamentals as revealed by in-situ and ex-situ nano- characterization and theory}

The complex coupling of electrochemistry, thermodynamics, and transport phenomena, and its immense potential to transform energy-storage in many fields, makes the Li-S battery very fertile ground for scientific research that bridges many fields. Unfortunately, Li-S cells have for the most part been studied as 'black boxes' with few published works focused on understanding the principles that define the limits of performance and operation. Based on the apparent clarity of the issues raised in the introduction, it is perhaps tempting to conclude that this neglect is justified, as the key mechanisms are already well understood. Reality is unfortunately inconsistent with this view and there remain multiple controversial perspectives. Scheme 2a [27] summarizes the four critical types of reactions currently thought to occur in the sulfur cathode. They are fragmentation reactions (I); electrochemical reduction reactions of elemental sulfur and lithium polysulfides (II); association or dissociation reactions of polysulfides (III); and chemical reactions of lithium polysulfides with nonaqueous electrolyte (IV). On the anode side of the cell, complex reactions also occur with lithium metal, including the reaction of lithium metal with electrolyte $(\mathrm{V})$ and the reaction of lithium metal with lithium polysulfides (VI). 


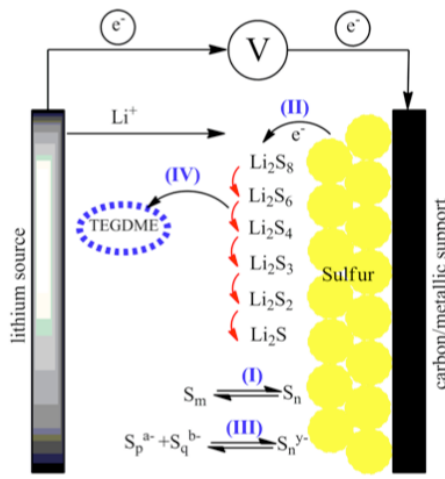

(a)

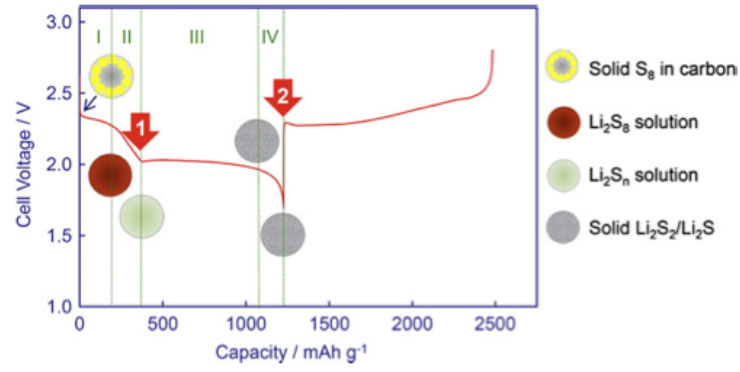

(b)

Scheme 2. (a) Schematic of the Critical Reactions in a Li-S Cell. Reprinted with permission from [27]. Copyrights 2014 American Chemical Society (b) A typical discharge and charge voltage profile of the first cycle of $\mathrm{Li} / \mathrm{S}$ cell. Reprinted with permission from [28]. Copyrights 2012 Elsevier.

Correspondingly, Scheme $\mathbf{2 b}$ shows a typical discharge and charge voltage profile for the first cycle of a Li-S battery[28]. Based on the phase change of sulfur species, the discharge process is typically divided into four reduction regions: Region I: A solidliquid two-phase reduction from elemental sulfur to $\mathrm{Li}_{2} \mathrm{~S}_{8}$, which produces the upper voltage plateau during discharge at 2.2-2.3 V. Region II: A liquid-liquid single-phase reduction from the dissolved $\mathrm{Li}_{2} \mathrm{~S}_{8}$ to low-order LiPS, during which the discharge voltage steeply declines and the solution's viscosity gradually increases. Region III: A liquidsolid two-phase sequential reduction from the dissolved low-order LiPS to insoluble $\mathrm{Li}_{2} \mathrm{~S}_{2}$ or $\mathrm{Li}_{2} \mathrm{~S}$, which is responsible for more than $60 \%$ of the theoretical capacity of the cell. Region IV: A solid-solid reduction from insoluble $\mathrm{Li}_{2} \mathrm{~S}_{2}$ to $\mathrm{Li}_{2} \mathrm{~S}$.

Intrusive experimentation using the modern analytical tool set for nanotechnology in principle provides a complementary approach for elucidating the fundamental processes at work in the Li-S cell. Table 1. summarizes the most commonly used methods for interrogating reaction pathways in the Li-S battery. This list is considerably shorter than typically found in other areas of nanomaterials science because interrogation of the Li-S cell is, unfortunately, limited by several factors: (i) Some of the key intermediates in the charge/discharge states identified by theory are unstable and may associate or disassociate to form other, more stable species; (ii) The charge/discharge intermediates and products are all sensitive to the air and moisture, and can change under high vacuum. This provides very strong limitations on which tools can be used to quantify the amounts and to define the potentials at which each of the multitude of intermediate species proliferate; (iii) the intermediates appear to always co-exist, which means that it is never really practical to separate individual species for indept studies; (iv) lithium is a light, very active element and the ability to detect it in ionic form is limited.

\begin{tabular}{|c|c|c|}
\hline Techniques & Property characterized & $\begin{array}{l}\text { Representative study } \\
\text { (reference number) }\end{array}$ \\
\hline Transmission electron microscopy (TEM) & Size, shape and crystallinity & {$[29,30]$} \\
\hline Scanning electron microscopy (SEM) & Shape/assembly structure & {$[31-33]$} \\
\hline
\end{tabular}




\begin{tabular}{|c|c|c|}
\hline X-ray diffraction (XRD) & Crystal structure & {$[34-39]$} \\
\hline UV-vis Spectroscopy & $\begin{array}{c}\text { Light absorption and scattering/Species } \\
\text { identification }\end{array}$ & {$[40-43]$} \\
\hline X-ray photoelectron spectroscopy (XPS) & $\begin{array}{c}\text { Chemical composition/binding } \\
\text { information }\end{array}$ & {$[44-47]$} \\
\hline Energy dispersive X-ray analysis (EDX) & Chemical composition & {$[29,50]$} \\
\hline Atomic force microscopy (AFM) & Shape, size, and work function & {$[39,47,51-53]$} \\
\hline Near-edge X-ray absorption fine structure \\
(NEXAFS/XANES) & Chemical composition/oxidation state & {$[47]$} \\
\hline X-ray emission Spectroscopy (XES) & & Electron band gap \\
\hline Chemisorption and physisorption & Surface area/hole size & \\
\hline
\end{tabular}

Table 1. Summary of the most commonly used nanomaterials characterization techniques used for elucidating solution and solid-state behaviors in Li-S cells.

X-ray diffraction (XRD) has proven to be a powerful technique to follow the lithium insertion mechanism in Li-ion batteries. In the Li-S system, as the redox reaction is accompanied by phase transformation (solid-liquid phases) of active material, structural and morphological changes occur at the positive electrode. Abruna and co-workers [39] employed a combination of in-situ X-ray diffraction (XRD) and K-edge X-ray absorption near edge structure (XANES) to perform inoperando investigations of Li-S cells with $\mathrm{PVDF} /$ tetraglyme-LiClO 4 gel-polymer electrolytes. These studies confirm that crystalline $\mathrm{S}_{8}$ transitions to non-crystalline LiPS in region I and that by the end of region IV, fully reduced crystalline $\mathrm{Li}_{2} \mathrm{~S}$ is observed. Both sets of observations are consistent with results reported in other in-situ X-ray studies [34-36]. However, there is disagreement about at what stage in the cell discharge $\mathrm{Li}_{2} \mathrm{~S}$ is observed. Specifically, in situ synchrotron-based results clearly indicate formation of crystalline $\mathrm{Li}_{2} \mathrm{~S}$ on the positive electrode at the very beginning of Region III, whereas the study by Abruna et al suggest that $\mathrm{Li}_{2} \mathrm{~S}$ is formed near the end of region III. This is an important difference because it has consequences for the reaction mechanism. A remarkable pair of results from all in-situ XRD studies is that $\mathrm{Li}_{2} \mathrm{~S}$ disappears completely from the cathode during cell recharge and that sulfur initially present in the orthorhombic state, first disappears during discharge and reappears during charge in the form of another allotrope: monoclinic b-sulfur.

A much larger number of ex-situ XRD studies of the Li-S battery cathode have been reported [29, 31-33, 37, 38, 58, 59]. While most of these works confirm the results reported from the in-situ work, namely that crystalline $S_{8}$ present in the electrode at the beginning of discharge gradually gives way to cubic crystalline $\mathrm{Li}_{2} \mathrm{~S}$ by the end of discharge $[32,37,58]$, as with the in-situ studies there is discrepancy about where in the discharge process the $\mathrm{Li}_{2} \mathrm{~S}$ is first observed $[33,38]$. There are also discrepancies about whether the $\mathrm{Li}_{2} \mathrm{~S}$ formed on the cathode can be completely removed by recharge. The insitu XRD studies by Abruna and coworkers [39], show that $\mathrm{Li}_{2} \mathrm{~S}$ is completely removed upon cell recharge, but the authors only reported results for a single cycle of charge and discharge. These findings disagree with other reports [31] where traces of $\mathrm{Li}_{2} \mathrm{~S}$ can still 
be observed in the cathode of Li-S cells subject to more cycles of discharge and charge. Considering the notoriously poor electronic and ionic conductivity of $\mathrm{Li} 2 \mathrm{~S}$, it is likely that the material gradually builds up in the cathode over prolonged cycling [31, 60]. Divided opinions also exist about sulfur disappearance and reappearance in the cathode during Li-S battery cycling exists as well. In general, researchers agree that x-ray diffraction associated with crystallized sulfur disappears during initial discharge of a Li-S battery, even when care is taken to interrupt the cell at different depths of discharge [33, 37, 38]. However, some studies reported the accumulation sulfur in the cathode during prolonged cycling[29], particularly at high C-rates [32]. Sulfur formation at the end of charge has also been reported in some cases [38, 59] whereas in others soluble polysulfides formed during the initial discharge are argued to remain in solution throughout cell operation and to not transform back to solid $\mathrm{S}_{8}[11,31,33,37]$. These studies underscore the richness of the electrode processes and highlight the need for more in-dept work using other techniques.

The XANES study by Abruna and co-workers (Figure 6) is unique among in-situ studies of Li-S cells because it provides information about both the crystalline and amorphous species. One key finding from this work is that the clear demarcation of the four reaction regimes depicted in Scheme 2b and the equally popular cartoons (Figure 3) that summarize understanding of the reactions that occur in each of these regimes may be gross over simplifications. In particular, the authors reported non-negligible concentrations of a multitude of high order LiPS species in region II and show evidence that these species undergo a complex set of disproportionation reactions to form the primary electroactive species $\mathrm{LiS}_{3}$ responsible for the plateau in Region III (shown in Scheme 2b). The appearance of fully crystalline $\mathrm{Li}_{2} \mathrm{~S}$ at the end of discharge is argued to occur by disproportionation of the reduction product, $\mathrm{Li}_{2} \mathrm{~S}_{3}$, at the end of region III, rather than by the sequential electrochemical reduction process typically assumed. An important consequence of this study is that even at $>90 \%$ conversion of LiPS produced by the end of Region I, the overall cell capacity is at most $64 \%$ of the theoretical capacity. Thus, the presence of sulfur as electrochemically-inactive polysulfides can reasonably account for a significant fraction of the discrepancy between the theoretical and actual storage capacity reported for Li-S cells. XANES was also used by the Nazar group [51] to fundamentally understand how the complex solution electrochemistry and physical chemistry of sulfur compounds impact active material utilization and capacity. The authors attributed the limited capacity to the disproportionation reaction of $\mathrm{S}_{8}{ }^{2-} \rightarrow \mathrm{S}_{6}{ }^{2-}+\mathrm{S}_{8}$. Although superficially different from the conclusion reached in [39], both studies are consistent and in our view correct in underscoring the fact that the many and complex disproportionation reactions produced by subtle changes of electrolyte or cell running conditions are an overlooked aspect of Li-S cell operation that can be revealed by XANES. 

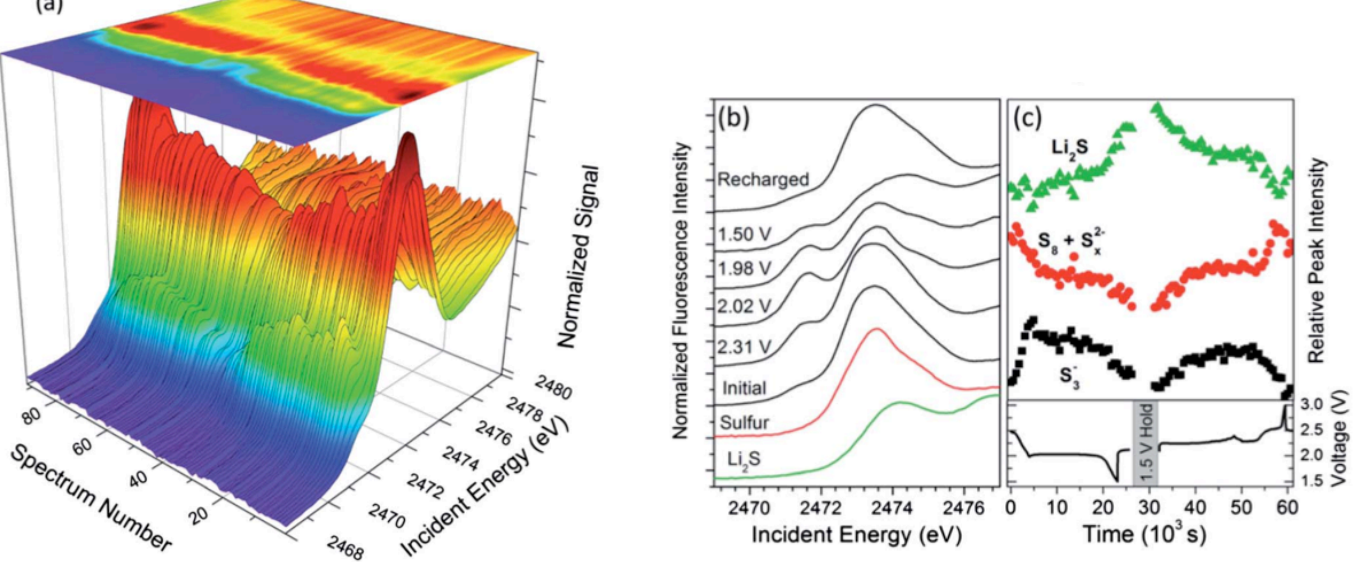

Figure 6. XAS data for a lithium sulfur battery with a gel polymer elec- trolyte. (a) Waterfall plot of dataset for a full galvanostatic cycle. (b) Spectra selected from specific points during the cycle. (c) Variation of fluorescence signal and cell voltage as a function of charge. Data points correspond to the intensity of the first derivative of each spectrum at $2471.1 \mathrm{eV}$ (pre-peak, black), $2472.6 \mathrm{eV}$ (main peak, red), and $2473.9 \mathrm{eV}$ ( $\mathrm{Li}_{2} \mathrm{~S}$, green) Reprinted with permission from [39]. Copyrights 2014 The Royal Society of Chemistry.

Identification of sulfide species formed during the charge/discharge process is critical in understanding the mechanism. U-vis spectroscopy is another powerful characterization tool and provides insight not only into the overall chemical composition of LiPS in electrolytes, but also potentially about the time-dependent concentration of each LiPS component. Barchasz et al [42], for example, used this method to investigate the electrolyte composition at different discharge potentials in a TEGDME-based electrolyte. They showed that besides the more familiar electrochemical reductions, there are complicated chemical reactions between PS anions in the electrolyte solution: $\mathrm{Li}_{2} \mathrm{Sn}+\mathrm{Li}_{2} \mathrm{~S} \rightarrow \mathrm{Li}_{2} \mathrm{~S}_{n-m}+\mathrm{Li}_{2} \mathrm{~S}_{1+m} ; \mathrm{Li}_{2} \mathrm{~S}_{n} \rightarrow \mathrm{Li}_{2} \mathrm{~S}_{n-1}+1 / 8 \mathrm{~S}_{8}$. Also, the deposition of insulating $\mathrm{Li}_{2} \mathrm{~S}$ results in electrode passivation and an early ending of discharge resulting in an incomplete end product $\mathrm{Li}_{2} \mathrm{~S}_{2}$ : controlling the deposition of $\mathrm{Li}_{2} \mathrm{~S}$ might then be a critical point for achieving the full capacity of Li-S cell. Patel et al [40] carried out what appears to be the first UV-vis spectroscopy study of a Li-S battery in operando. The authors showed that it is possible to establish qualitative and quantitative differences between soluble polysulfides in the catholyte. They also show that there are characteristic absorption wavelengths for each type of polysulfides and confirmed that the UV spectra of a range of catholyte solutions were correlated to the natural logarithm of concentration in agreement with the Beer-Lambert law. These experiments suggest that dissolved polysulfides are in equilibrium and there is a much larger content of certain mid-length polysulfide species present in the electrolyte at the end of charging process. Interestingly, those two points are precisely those reported in the XANES study discussed earlier. A year later, the same group extended the UV-vis study to investigate two electrolyte systems and to relate their observations to macroscale features of Li-S battery performance [41]. It was found that the capacity of Li-S cells fade more quickly in sulfolane-based electrolytes than in TEGDME:DOL and that the higher solubility of LiPS in the sulfolane-based electrolyte leads to higher irreversible loss of active material. Most interesting, from a battery performance perspective, among these observations is that a maximum concentration of about $30 \mathrm{mM}$ of polysulfides is achieved in the 
electrolyte at the beginning of the low-voltage plateau (the beginning of Region III in Scheme 2(b)), which provides the first direct correlation between the apperance of the dip in the discharge curve and a viscosity spike in the electrolyte [28].

In addition to providing insights into the electrochemistry in Li-S battery electrolytes, these tools have also been used to correlate changes in morphology at the Li-S cell electrodes to performance. Aurbach et al. reported morphological and structural studies of composite sulfur electrodes by AFM [29]. They found that the ratio of the conductive surface area to the total scanned surface area of a pristine electrode is close to $90 \%$, but less than $30 \%$ of the surface is still conductive after 6 cycles of discharge and charge (Figure 7). This finding agrees with the findings from $\mathrm{x}$-situ XRD studies that the electrode is covered by an insulting layer, which could be a critical factor that results in the capacity fading. These findings are largely in line with a much larger body of work based on ex-situ SEM [31-33], TEM [29, 30], Raman [29, 30, 61] and in-situ electrochemical impedance spectroscopy [50], which all show that if no special effort is made to sequester sulfur in the cathode, most of the sulfur in the cathode disappears at the end of region II of the discharge. Visualization studies using flow cells show that the disappearance is linked to dissolution of Li-PS in the electrolyte. These studies also confirm that the electrode is covered by a film at the end of discharge due to the precipitation $\mathrm{Li}_{2} \mathrm{~S}$, which increases the interfacial resistance of the cathode.

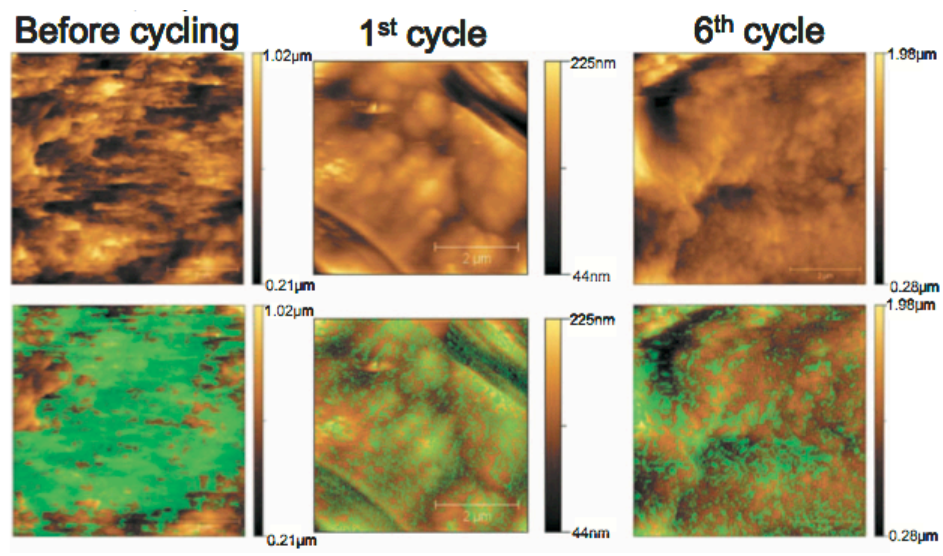

Figure 7. AFM topography and conductivity images of sulfur composite electrodes that underwent different numbers of cycles as indicated. Top row: Topography images; bottom row: Conductivity mapping superimoposed on the topography images. Reprinted with permission from [29]. Copyrights 2010 The Electrochemical Society.

With the growing trend of incorporating nanomaterials into the Sulfur cathode for improving cell performance, other nano-characterization tools have received commensurate attention for understanding the mechanisms through which these materials function. For example, porous nanocarbons have been used as the host of sulfur because of lots of advantages which we will discuss in detail in the next section. Thus chemisorption and physisorption is used to characterize the surface area and pore size of the carbon host, which are important parameter of the system[54-57]. Also, in the carbon/sulfur composite, the distribution of the sulfur in the carbon matrix is important in determining the performance, and EDX is a powerful tool to map the individual 
elementary distribution[48, 49]. In addition, additives with multiple function are used, for the reason that they can interact with polysulfide to contain the capacity. In those work, XPS is widely used as a tool to probe the interaction between sulfur species and the function group/atom of the additives[44-46].

Computer stimulations provide complementary insights into the electrochemical reactions in Li-S cells. Chen [62] reported DFT simulations of $\mathrm{Li}_{2} \mathrm{~S}_{\mathrm{n}}(\mathrm{n}=1 \sim 8)$ clusters in the discharge reaction and found that the stability of $\mathrm{Li}_{2} \mathrm{~S}_{\mathrm{n}}(1<\mathrm{n}<8)$ increases with decreasing $\mathrm{n}$, explaining the favorable thermodynamics of the reduction of $\mathrm{S}_{8}$ to $\mathrm{Li}_{2} \mathrm{~S}$. In a careful study, Moore [27] presented a comprehensive set of predictions based on thermochemical data for possible reactions in the Li-S system using high-level quantum chemical methods. The computed Gibbs free energies for the dissociation/association of polysulfide anions and lithium polysulfides in solution were used to develop a detailed reaction network for the discharge process. This analysis supports the existence of the following major intermediates, $\mathrm{S}_{2}{ }^{2-}, \mathrm{S}_{3}{ }^{2-}, \mathrm{S}_{4}{ }^{2-}, \mathrm{S}_{3}{ }^{1-}$, and shows that upon complete utilization of $\mathrm{S}_{8}{ }^{2-}$. the most abundant intermediate in solution is $\mathrm{S}_{3}{ }^{2-}$, in agreement with the earlier inferences from in-situ XANES studies. These findings are significant because they imply that a successful strategy to maximize sulfur utilization in a Li-S cell is to use cells based on electrolytes enriched with $\mathrm{Li}_{2} \mathrm{~S}_{3}$. As a proof-of-concept, we demonstrate the potential benefits of this approach in Figure 8. These results were obtained using Li-S cells with the electrode made of physical mixture of elementary sulfur $(50 \%)$, carbon black $(40 \%)$ and PVDF binder $(10 \%)$, i.e. no special effort was made to sequester sulfur or its reduction compounds in the cathode. The amount of sulfur in each cell is $\sim 1 \mathrm{mg}$ and the volume of electrolyte is $40 \mathrm{uL}$. With the addition of $\mathrm{Li}_{2} \mathrm{~S}_{3}$ to the electrolyte $\left(0.1 \mathrm{M} \mathrm{Li} \mathrm{L}_{3}\right.$, $0.2 \mathrm{M} \mathrm{LiNO}_{3}, 1 \mathrm{M} \mathrm{LiTFSI}$ ), significant improvements in both the discharge capacity and cycleability are observed. The size of the improvements can be better appreciated by removing the contribution from $\mathrm{Li}_{2} \mathrm{~S}_{3}$ makes to the discharge capacity (open symbols).

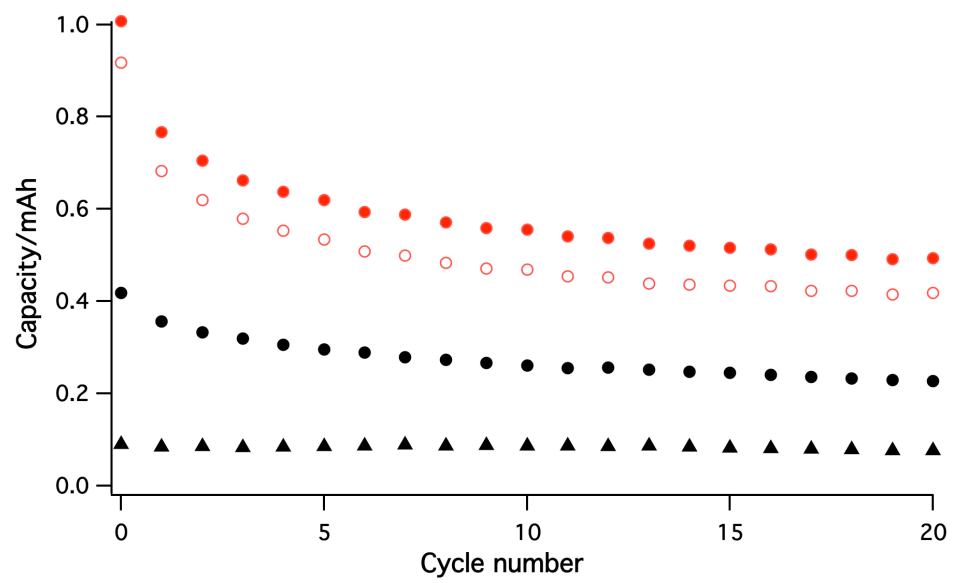

Figure 8. Capacity versus cycle number for a $\mathrm{Li}-\mathrm{S}$ containing a $\mathrm{Li}_{2} \mathrm{~S}_{3}$-enriched electrolyte before (filled red circles) and after (open red circles) removing the contribution of $\mathrm{Li}_{2} \mathrm{~S}_{3}$ in the electrolyte (black triangle). Results from the control experiment in which no Li2S3 is added to the electrolyte are indicated as black filled circles. We believe that when coupled with some of the beneficial effects already achieved by incorporating nanomaterials into the battery cathode, a $\mathrm{Li}_{2} \mathrm{~S}_{3}$ enriched electrolyte provides a promising path forward. 
Shuttling of the dissolved polysulfide species in the Li-S battery has been studied theoretically by Akridge and coworkers [63] using a continuum approach. In particular, beginning with the basic Nernst equations for each of the two plateaus and a diffusion/reaction term that describes the shuttle process, and by imposing a sulfur species balance and a charge balance. The authors were able to theoretically describe the charge and discharge profiles in the Li-S cell. Significantly, this work elegantly shows that self-discharge, poor charge-discharge efficiency, asymmetry of the charge profile, and overcharge protection are all facets of the same phenomenon in the Li-S cell.

\section{Nanomaterials designs for sequestering sulfur in the cathode}

Three of the four barriers to development of a practical Li-S cell that live up to the promise of the technology can be directly traced to the cathode. It is therefore unsurprising that development of functional cathode designs capable of overcoming these barriers has been a high priority for research. Cathodes based on components capable of achieving the necessarily electronic conductivity, of accommodating volume changes associated with the lithiation and delithiation reaction, and most importantly, which prevent polysulfide dissolution are an area of active study worldwide. Although largely driven by intuition the large improvements in capacity and cycling performance produced by even small changes in the electrode and electrolytes can be readily understood in terms of the mechanistic insights from in-situ analysis of the Li-S cathode. Incorporation of high-surface area and electrically conductive nanomaterials in the sulfur cathode have, for example, been demonstrated over the last decade lead to significant improvements in discharge capacity and lifetime. We focus first on the role nanostructures capable of trapping sulfur and polysulfides in the cathode using physical/kinetic and chemical/thermodynamic sequestration have played in improving the design and performance of the sulfur cathode in Li-S cells.

\section{III.1 Sequestering sulfur in the cathode using physical forces}

The strong interaction of sulfur with carbon and the synergetic effects the carbon brings in terms of enhancing the conductivity of the cathode has led to an upsurge in interest in cathodes based on sulfur-carbon nanocomposites[64]. The morphology of the carbonsulfur nanocomposite is now understood to influence everything from the cycling performance,[65, 66] propensity of the cells to self-discharge,[67] and the LiPS shuttle.[68, 69]

\section{III.1.1 Sulfur infused into porous carbon matrices}

Carbonaceous materials with high porosity are widely used as conductive agents and as cathode hosts/matrices to trap the active polysulfide species in the cathode during cell operation. The perspective provided by the XANES studies by Abruna and co-workers provides straightforward justification for these efforts in terms of their ability to increase active material utilization. In addition, if the carbonaceous materials are engineered to contain sulfur in nanometer sized pores that can better accommodate volume expansion and strain they are expected to stabilize the mechanical properties of the cathode and 
hence enhance the Li-S cell lifetime. Thus in addition to its effect on sulfur sequestration and active material utilization, the pore size also affects other features such as the ease with which electrolyte can infiltrate the cathode and the rate with which electrons can be transported to/from the active material. Pore size and pore volume of the nanocomposite materials can therefore affect myriad aspects of the Li-S cell performance, including the plateau voltage, active material utilization, rate capability, discharge capacity, and capacity retention.

Porous carbon is classified as microporous (pore diameter less than $2 \mathrm{~nm}$ ), mesoporous (2 to $50 \mathrm{~nm}$ ) or macroporous (larger than $50 \mathrm{~nm}$ ). Reports on carbon-sulfur composites with a pore size greater than $10 \mathrm{~nm}$ show the typical two-plateau behavior of the sulfur electrode, which is similar to cathode without mesoporous carbon. In contrast, microporous carbon-sulfur composites have a slightly different voltage profile, with one plateau between 1.5 and $1.9 \mathrm{~V}$ vs. $\mathrm{Li} / \mathrm{Li}^{+}$[70] which attains most of the discharge capacity. It is likely that sulfur is no longer in the $\mathrm{S}_{8}$ cyclical structure in these composites; instead, small sulfur is formed due to the constrained pore volume and sulfur and carbon are mixed at the atomic level $[65,71]$. Consequently, the corresponding Gibbs free energy of the reaction is different because higher order polyfulfide formation process is excluded in the reaction.

Microporous carbon proves to be an effective sulfur immobilizer because it has extremely small pores to constrain sulfur and reaction by strong adsorption, which is able to prevent intermediate product polysulfides from outflowing into the electrolyte [72], as a result, long cycle life is often observed in the case [71, 73]. Zhang et al. [74] have obtained microporous carbon-sulfur composites with a narrow pore size distribution of about 0.7 $\mathrm{nm}$ after thermal treatment of sublimed sulfur and carbon spheres. This material delivers a large reversible capacity of $650 \mathrm{mAh} / \mathrm{g}$ even after 500 cycles at a current density of 400 $\mathrm{mA} / \mathrm{g}$, with a high coulombic efficiency as well. They have proposed that narrow micropores act as micro-reactors (shown in Figure 9) to confine all the electrochemical active species within the micropores and prevent sulfur and lithium polysulfides from releasing into the electrolyte such that the reversible capacity is improved. Guo et al. [65]have proved that, if the pore size of the carbon matrix is less than $0.5 \mathrm{~nm}$, sulfur exists as smaller chainlike $\mathrm{S}_{2-4}$ molecules due to limited pour volume. Thus, the higher order polysulfides that can dissolve into the electrolyte would not be formed during cycling process [75]. Smaller sulfur allotropes have become new starting active materials with the facilitation of microporous carbon materials. Despite exhibiting a good reversible capacity upon cycling, microporous carbon-sulfur composites have confined spaces that do not accommodate loaded active sulfur as well. It results in limited weight ratio of activate sulfur materials in the cathode and low practical capacity of the whole cathode materials. 
Figure 9. A scheme of the constrained electrochemical reaction process inside the micropores of the sulfur carbon sphere composite cathode. Reprinted with permission from[74]. Copyrights 2010 The Royal Society of Chemistry.

Porous carbons with an increased pore volume can be used to enhance sulfur loading. For this reason, mesoporous materials have been studied extensively as hosts for sulfur[54, $56,76,77]$. The large pore sizes over those of microporous materials allow for easier access to sulfur by liquid electrolytes such that it can facilitate Li ion migration. Thus, lithium sulfur cells with mesoporous carbon-sulfur cathodes show an increase in voltage plateau. Early work in this area was performed by Wang et al. [64, 78], who used an activated carbon with a pore size of around $2.5 \mathrm{~nm}$ as the conductive matrix and achieved a reversible capacity of $400 \mathrm{mAh} / \mathrm{g}$. After that, Ji, Lee and Nazar [67] [79] have reported a highly ordered mesoporous carbon-sulfur cathode exhibiting high pore volume, uniform pore diameters and interconnected porous structure by employing a well-known mesoporous carbon material CMK-3, which is synthesized from a mesoporous silica template SBA-15. Their results show that this cathode renders a highly enhanced performance with reversible capacities up to $1320 \mathrm{mAh} / \mathrm{g}$. The intake of sulfur within the pores is accomplished by melt diffusion method, where sulfur and CMK-3 carbon mixture are heated together at $155^{\circ} \mathrm{C}$. The $\mathrm{CMK}-3 /$ sulfur composite electrode was shown to exhibit a high initial discharge capacity of $1005 \mathrm{mAh} / \mathrm{g}$, and it was improved to 1320 $\mathrm{mAh} / \mathrm{g}$ by linking the carbon surface with polyethylene glycol (PEG) to further trap polysulfides. The highly porous carbon-sulfur composite reported by Lai [80] with $57 \mathrm{wt}$ $\%$ sulfur loading delivers the initial high specific capacity up to $1155 \mathrm{mAh} / \mathrm{g}$ and a stable capacity of $745 \mathrm{mAh} / \mathrm{g}$ after 84 cycles at the current density of $40 \mathrm{~mA} / \mathrm{g}$. On the basis of the analysis of the microstructure and electrochemical performance, they confirmed that the composite could effectively prevent the shuttle behavior of the lithium-sulfur battery. 
In designing mesoporous carbon-sulfur cathodes, factors such as pore size, pore volume and sulfur loadings are essential for improving the performance. The pore size and volume effects have been investigated by $\mathrm{Li}$ et al. [77], who studied a series of mesoporous carbon materials with tunable pore sizes ranging from $3 \mathrm{~nm}$ to $22 \mathrm{~nm}$ and pore volumes ranging from 1.3 to $4.8 \mathrm{~cm}^{3} / \mathrm{g}$. The authors reported that the overall electrochemical performance of Li-S cells based on electrodes containing carbon with different pore sizes are very similar if the sulfur loading is sufficiently high to fill the pores with sulfur. However, by partially filling the pores with sulfur, they observed improved utilization of the active material and enhanced cycling performance. This finding can be rationalized in terms of the competing beneficial effects of sulfur sequestration and optimized electrical contact with the mesoporous substrate with the less attractive features of a sulfur-filled pore, such as limited access to the electrolyte, reduced dissolution/diffusion of polysulfides and sluggish transport of lithium ions.

Carbons with bimodal pore structure, which combines microporous with mesoporous elements were first reported as cathode hosts for Li-S cells by Liang et al. [72]. Other researchers have recently performed more in-depth studies of Li-S cells incorporating this type of carbon $[54,76,81]$. In general, carbon with a bimodal pore structure is believed to offer multiple advantages. The small pores can confine polysulfide species to prevent their outflow, while the large pores are in favor of accommodating the liquid electrolyte where lithium ions have high conductivity. He et al. [81] have synthesized sulfur bimodal porous carbons as the cathode for lithium sulfur cells cycled at high rate with an evaporation-induced self-assembly approach. They have obtained the desired bimodal distribution by optimizing the carbon: silica: surfactant ratio and demonstrated an initial capacity of $995 \mathrm{mAh} / \mathrm{g}$ and a capacity of $550 \mathrm{mAh} / \mathrm{g}$ after 100 cycles at $1675 \mathrm{~mA} / \mathrm{g}$ rate. In addition, mesoporous silica, which is believed to increase hydrophilicity and help trap more polysulfides, has been applied in this work to enhance the cycle stability. Liang et al. [72] reported a carbon-sulfur nanocomposite based on a hierarchically structured micro-mesoporous carbon formed by a post-activation treatment. Sulfur was loaded solely into the microporous wall by a wet-impregnation method. The empty mesopores function as reservoirs for the soluble polysulfide ions formed during cycling. They also find that utilization of sulfur is strongly affected by the active mass fraction. A composite containing $11.7 \mathrm{wt} \%$ sulfur exhibits a first discharge capacity of $1584 \mathrm{mAh} / \mathrm{g}$ even at a very high current rate of $2500 \mathrm{~mA} \mathrm{~g}^{-1}$. Increasing the composite's sulfur content to $51.5 \%$ gives a decreased discharge capacity of $818 \mathrm{mAh} / \mathrm{g}$ at first cycle. Rapid capacity fading is observed in all cases. A core-shell structure, in which sulfur cores are encapsulated by carbon shells, can improve sulfur loading without compromising cycleability. Li et al. [54] reported an ordered meso-microporous core-shell (MMCS) carbon as a sulfur container(shown in Figure 10). The core part of the composite with large pore volume and highly ordered porous structure promises a sufficient sulfur loading and a high utilization of the active material, while the shell containing microporous carbon and smaller sulfur acts as a physical barrier and stabilizes the cycle capability of the entire composite. The composite exhibits a capacity as high as $837 \mathrm{mAh}$ $\mathrm{g}^{-1}$ at $835 \mathrm{~mA} / \mathrm{g}$ after 200 cycles with a high capacity retention of $80 \%$ vs. the second cycle. This bimodal structure can greatly reduce the diffusion of polysulfides into the bulk electrolyte. 
(a)

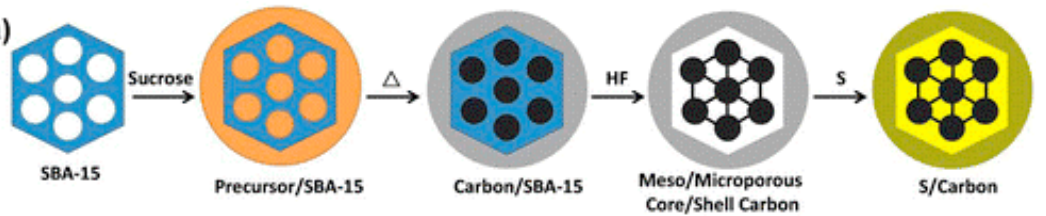

(b)

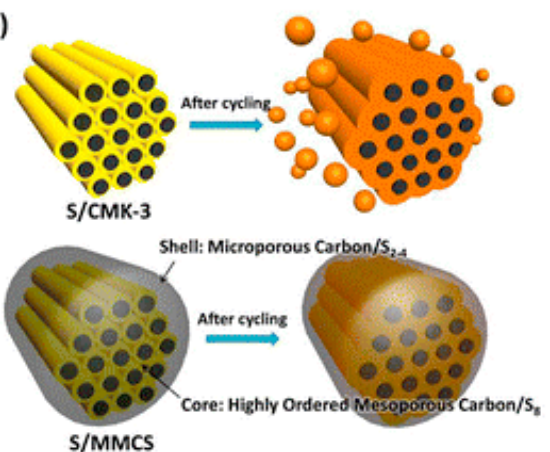

Figure 10. (a) Schematic for preparation of highly ordered meso-microporous core-shell (MMCS) carbon and sulfur/carbon composite. (b) Schematic of the mesoC/S $\mathrm{S}_{8}-\mathrm{microC} / \mathrm{S}_{2-4}$ coreshell structure. Reprinted with permission from [54]. Copyrights 2014 American Chemical Society.

Macroporous carbons with pore sizes greater than $100 \mathrm{~nm}$ show no advantage on preventing shuttling upon cycling and have been investigated less as cathode for lithium sulfur system. Macroporous carbon has open structures that cannot effectively retain sulfur and intermediate polysulfides within pores. Wei et al. [82] have adopted $\mathrm{KOH}$ activation to obtain hierarchical porous structure including macropores derived from pig bone. Despite a high initial capacity of $1265 \mathrm{mAh} / \mathrm{g}$ is observed, the capacity decreases to $643 \mathrm{mAh} / \mathrm{g}$ only after 50 cycles. The substantial decay in capacity suggests that macroporous carbons are not ideal candidates for lithium sulfur cathodes.

\section{III.1.2 Sulfur infused into anisotropic carbon nanostructures}

One-dimensional (1-D) carbon nanostructures offer unique features for addressing problems related to conductivity and active material retention and utilization in a sulfur cathode. The conductive matrix created by the one-dimensional percolated carbon network provides better electrical connection to the active materials. In addition, novel designs of the 1-D nanostructured carbon can potentially address the previously mentioned difficulties in mechanical durability of sulfur cathodes. Ahn et al. [83] reported sulfur-containing multiwalled carbon nanotubes (MWCNTs) via a direct precipitation method for the cathode. In this case, sulfur is not trapped by or bonded strongly to nanotubes. As a result, a very low discharging capacity was observed upon 30 cycles. To achieve a stronger interaction between MWCNTs and sulfur, Yuan et al. [84] have taken advantage of the capillary effect between the sulfur and MWCNTs to construct a novel electrode with carbon nanotube as the core. This composite shows a good cycle life compared to the counterpart made by simply mixing sulfur with MWCNTs. However, a low initial capacity with only $650 \mathrm{mAh} / \mathrm{g}$ is observed. The reason is probably that sulfur is directly coated on the surface of the MWCNT host, resulting in the easy dissolution of polysulfide during cycling. 
Chen et al.[85] have developed three dimensional (3D) multi-walled carbon nanotubes to house sulfur or lithium sulfide, and achieved much enhanced capacity with $780 \mathrm{mAh} / \mathrm{g}$ remaining after 200 cycles at a current density of $500 \mathrm{~mA} / \mathrm{g}$. They believe that $3 \mathrm{D}$ carbon nanotube structures can buffer the stress caused by the volume expansion of sulfur upon discharging [85], and retard the out-diffusion of sulfur-based materials from electrodes [86]. Besides, the pores existing in such 3D structures can facilitate electron diffusion while allowing fast ions transport. Recently, a novel tube-in-tube carbon nanostructure (TTCN) with MWNTs confined within hollow porous carbon nanotubes is synthesized for Li-S cells by Zhao et al. [68]. MWNTs were encapsulated into hollow porous carbon nanotubes through a step-by-step strategy (shown in Figure 11). This structure is designed to enhance the electrical conductivity, hamper the dissolution of lithium polysulfide, and provide large pore volume for sulfur impregnation. As a cathode material for Li-S cells, the S-TTCN composite withholds a high sulfur content of $71 \mathrm{wt} \%$. At a current density of $500 \mathrm{~mA} \mathrm{~g}^{-1}$, a high discharge capacity of $918 \mathrm{mAh} / \mathrm{g}$ remained after 50 cycles, demonstrating high reversible capacity and good cycling performance as well as excellent rate capabilities.

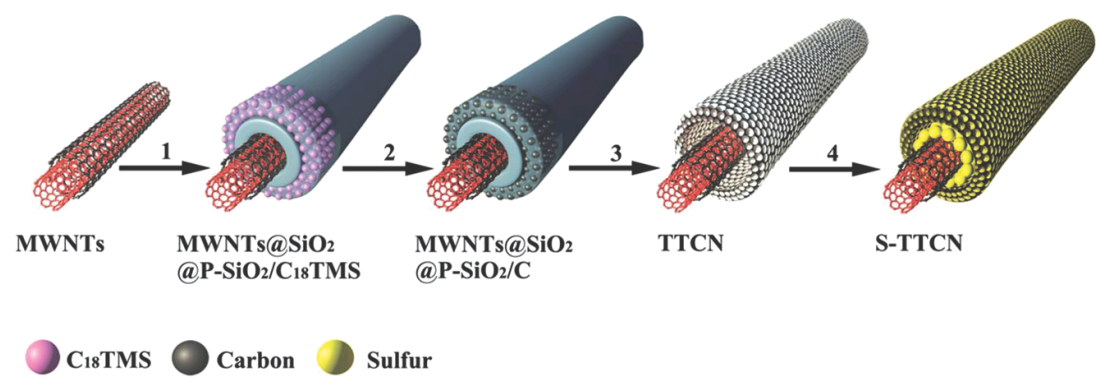

Figure 11. Schematic illustration for the formation of S-TTCN composite: (1) Uniform coating a solid $\mathrm{SiO}_{2}$ layer and a porous $\mathrm{SiO}_{2}$ layer embedded with $\mathrm{C}_{18}$ TMS molecules on MWNTs; (2) formation of porous carbon nanotube by carbonization of $\mathrm{C}_{18} \mathrm{TMS}$; (3) etching $\mathrm{SiO}_{2}$ layers to obtain tube-in-tube carbon nanostructure (TTCN) with MWNTs encapsulated within hollow porous carbon nanotube; (4) sulfur infused into TTCN to fabricate S-TTCN composite. Reprinted with permission from [68]. Copyrights 2014 Wiley-VCH Verlag GmbH \& Co. KGaA, Weinheim.

Porous carbon nanofibers have also recently been used for sulfur electrodes to reduce the amount of exposed sulfur. In this approach, carbon nanofibers from commercial activated carbon cloth [87] or electrospun polymeric precursors [57] were impregnated with sulfur. The commercial activated carbon fibers have a narrower pore size distribution, with a majority of the microporous structures smaller than $2 \mathrm{~nm}$. Hollow carbon nanofibers with a high aspect ratio have been shown to be effective in trapping sulfur. Moon and coworkers [17] have encapsulated sulfur into thin-walled carbon nanowires, which were obtained with the assistance of anodic aluminum oxide templates, demonstrating highrate electrochemical behaviors. They avoid of adding binders and other additives in cathodes, which increase the utilization of composite materials but results in continuous capacity fading. Zhang et al. [55] also reported the Li-S cells composed of colloidal microporous carbon nanofiber-encapsulated sulfur structures with unprecedented electrochemical performance and high specific capacity and good cycling stability (950

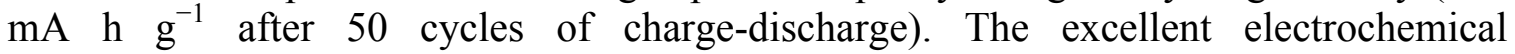


performance of the battery is attributed to their high-quality fiber morphology, controlled porous structure, large surface area, and good electrical conductivity.

One-dimensional nanotubes/nanofibers have to date proven insufficient for retarding polysulfide dissolution and shuttling due to their open-ended structure. Although nanostructures with open-ends are beneficial for the access of electrolytes and ion migration, these same structures also result in polysulfide leakage. Core/shell structures have been explored to address the challenge of open-end structures. In most core/shell structures, sulfur or sulfur-based compound acts as the core. Furthermore, high sulfur contents of approximately $85 \%$ embedded in the shell can be achieved [88]. In particular, the sulfur-carbon sphere composite with $42 \mathrm{wt} \%$ sulfur presents a long electrochemical stability up to 500 cycles, based on the constrained electrochemical reaction inside the narrow micropores of carbon spheres due to strong adsorption. Therefore, the electrochemical reaction constrained inside the micropores proposed here would be the dominant factor for the enhanced long stability of the sulfur cathode [74].

\section{III.1.3 Sulfur infused into hollow carbon nanostructures}

Modifying the core/shell carbon framework also provides a novel strategy for preventing polysulfide dissolution. This can be achieved either by making a hollow shell to allow easy access by the electrolyte or by making double shells to limit polysulfide dissolution. Jayaprakash et al. [13] reported Li-S battery cathodes based on a hollow carbon-sulfur nanocomposite in which the hollow carbon capsule was generated by a template-based approach (shown in Figure 12). In this method, Stober-derived $\mathrm{SiO}_{2}$ particles were in a first step conformally coated with a carbon precursor such as PAN, asphalt-derived pitch (Asp) or a polysaccharide (PS) such as glucose to form intermediate structures generically represented by the hairy nanopaticle cartoon in the figure. The authors reported that after etching away the $\mathrm{SiO}_{2}$ core and infusing sulfur via a vapor-phase procedure that relied on the low sublimation temperature of sulfur, S@C composite cathodes with impressive electrochemical features (high capacity retention of $91 \%$ after 100 cycles), can be obtained. They attributed the improvements to sequestration of elemental sulfur in the carbon capsules and to its favorable effect in limiting polysulfide dissolution, shuttling as well as to enhanced electron transport facilitated by the carbon shell. Zhang et al.[69] disclosed a novel carbon-sulfur nanocomposite synthesized by confining sulfur in double-shelled "soft" carbon hollow spheres with high surface area and porosity. With void space between the core and double shells, the volume expansion can be buffered. The double shell structure facilitates ion and electron transport as well. This carbon-sulfur nanocomposite shows an initial discharge capacity of $1020 \mathrm{~mA} \mathrm{~h} \mathrm{~g}^{-1}$ and a reversible capacity of $690 \mathrm{~mA} \mathrm{~h} \mathrm{~g}^{-1}$ after 100 cycles. 

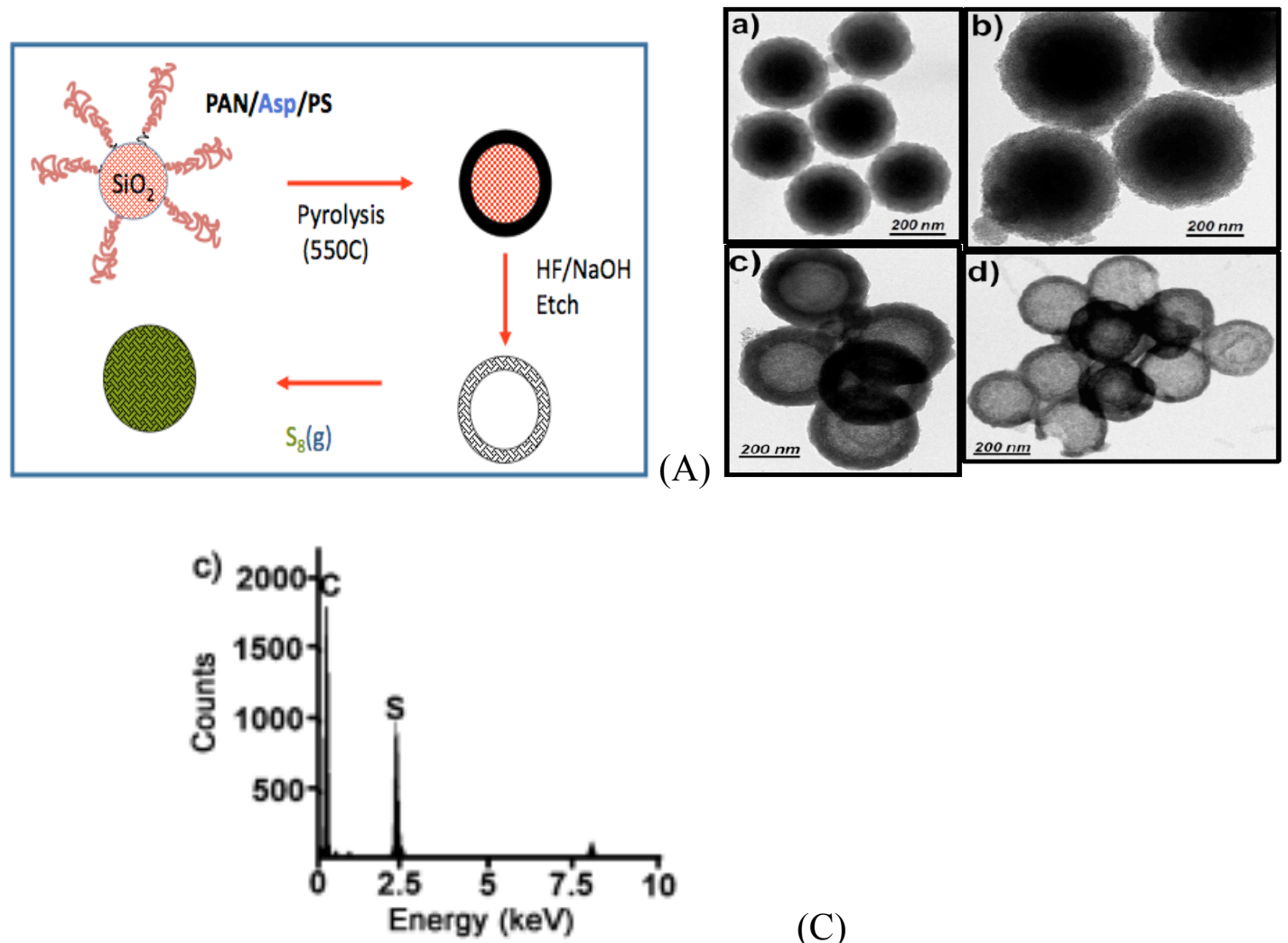

(C)

Figure 12. (A). Illustration of procedure used to create $C @ S$ nanocomposites created by infusing sulfur into carbon nanocapsules created by pyrolysis of polyacrylonitrile (PAN), Asphalt-derived pitch (Asp), or polysaccharides (PS) . (B). TEM images of a) mesoporous carbon hollow spheres b) C@S nanocomposite and (C). EDX analysis of C@S nanocomposite showing the presence of sulfur. Reprinted with permission from [13]. Copyrights 2011 Wiley-VCH Verlag GmbH \& Co. KGaA, Weinheim.

Nanoporous carbon-sulfur composites represent a clever method to improve the performance of the sulfur cathode, as shown in the examples above. To realize enhanced performance, the following aspects should be carefully considered: (1) optimized pore size and closed structure to trap polysulfides and minimize pulverization, (2) large pore volume to increase the content of sulfur for practical applications and (3) maximized amount of sulfur loading inside carbon pores. Given the tremendous potential of porous materials in Li-S battery applications, it will be highly beneficial if the kinetics associated to ion migration inside the nanoporous materials can be studied in more detail. It is also equally important to further study a variety of techniques to construct optimized porous materials.

\section{III.2 Sequestering sulfur in the cathode using specific chemical interactions}

Previously, sulfur cathodes have been designed to absorb polysuflides (PS) via various carbon matrices with optimal porosity and high surface area. However, the physical barrier created by carbon only delays the rate at which PS diffuse into the electrolyte. As a result, the kinetics associated with PS dissolution are only slowed initially and over time PS leach out of the electrode. Consequently, low capacity fade is often observed. 
Considering the weak Van der Waals interactions associated with the non-polar and hydrophobic carbon, these elements are too weak to contribute any appreciable adsorption effects. Furthermore, such methods often rely on expensive energy intensive methods to infuse the sulfur into the pores of the host material. As such, considerable attention to the use of surface-functionalized carbon materials as cathode material or metal oxides as cathode additive is currently being investigated. These materials possess polar chemical bonds and hydrophilic surfaces that provide chemical bonding with lithium polysulfides. In this way, the polysulfides produced during discharge is thermally sequestered in the cathode rather than temporarily capsuled.

Metal oxides have been utilized as either adsorbents or coatings to hinder the diffusion of LiPS. Nazar group has reported the use of porous $\mathrm{SiO}_{2}$ as a polysulfide reservoirs [89]. The polysulfide shuttle mechanism is suppressed to a large degree by incorporating SBA15 as an effective internal polysulfide reservoir, which permits adsorption/desorption in a reversible manner during the electrochemical reaction. Similar results were reported using mesoporous titania as an additive to the cathode [90]. Three types of mesoporous titania with different surface area, pore volume and pore size were investigated. The cathode was probed by FTIR and Raman to confirm the interaction between the Ti atom and sulfur species. The cathode with $\alpha-\mathrm{TiO}_{2}$ as additives maintained discharge capacities above $750 \mathrm{mAh} / \mathrm{g}$ after 200 cycles, achieved with less than $4 \mathrm{wt} \%$ content of additives. Other metal oxides, such as $\mathrm{Al}_{2} \mathrm{O}_{3}, \mathrm{La}_{2} \mathrm{O}_{3}$, and $\mathrm{Mg}_{0.6} \mathrm{Ni}_{0.4} \mathrm{O}$ were also reported to be effective as additives in immobilizing the sulfur and retarding polysulfide shuttling [9193]. Even as early as 2004, Hwang has patented several inorganic additives for Li-S cells, which included metal oxides, metal sulfides or a mixture thereof. Example metals include $\mathrm{V}, \mathrm{Al}, \mathrm{Zr}$, and Ti. Preferred are $\mathrm{V}_{2} \mathrm{O}_{5}, \mathrm{Al}_{2} \mathrm{O}_{3}, \mathrm{ZrO}_{2}$, and $\mathrm{TiS}_{2}$ [94]. A recent work published by Archer group [49] took advantage of molecular sorbents (TMS-PDTA and ionic liquid IM-Cl) to thermodynamically sequester sulfur species. The molecule were chosen because of the anchoring silane group which can tether to the carbon surface, and also because of the high binding energy towards LiPS calculated by DFT. This work is actually inspired by the former study carried out by the same group, which showed the ability of the PAN chains to pull $\mathrm{Li}_{2} \mathrm{~S}_{x}$ species out of solution, implying that the binding forces between $\mathrm{Li}_{2} \mathrm{~S}_{x}$ and PAN are strong and specific (Figure 13).

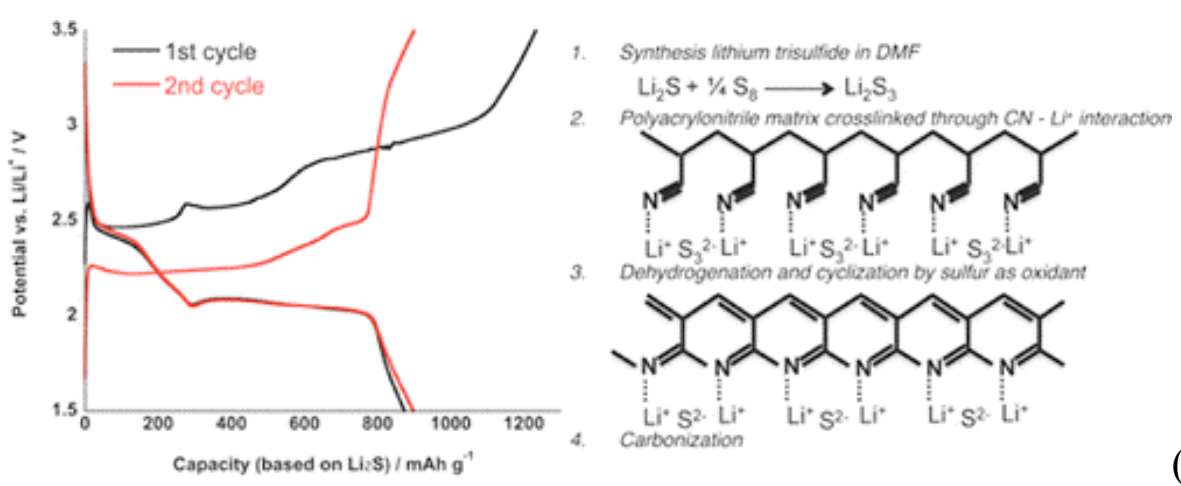




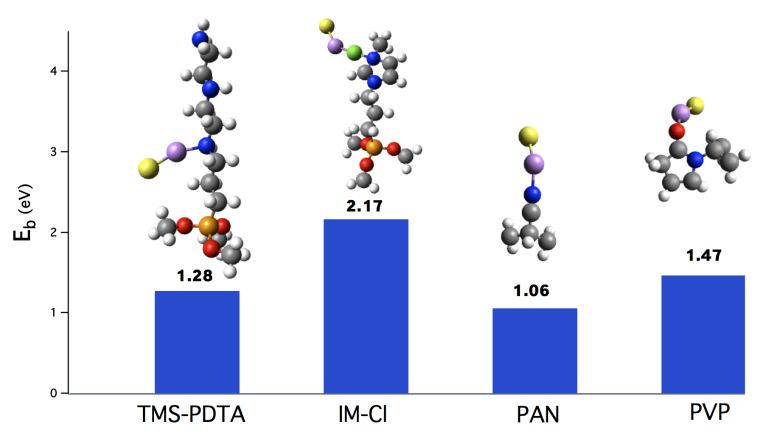

(b)

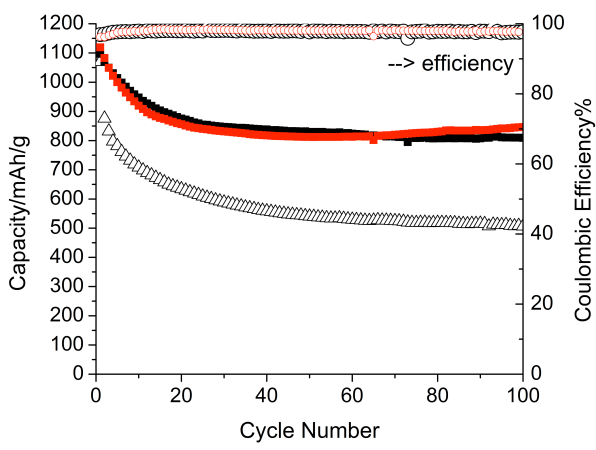

(c)

Figure 13. (a) PAN as a host for $\mathrm{Li}_{2} \mathrm{~S}$ cathode and the corresponding voltage profile. Reprinted with permission from [48]. Copyrights 2012 American Chemical Society. (b) DFT calculation of binding energy of different additives with polysulfide species. (c) Cycling performance of Li-S cell with additives of TMS-PDTA (black circle); IM-Cl (red circle); and no additives (black triangle). Reprinted with permission from [49]. Copyrights 2014 Wiley-VCH Verlag GmbH \& Co. KGaA, Weinheim.

Such studies have confirmed the importance of chemical interactions in hindering the migration of soluble polysulfides. Although they are effective in reducing dissolution of LiPS, oxides and molecular sorbents, are often inherently insulating, which means that complementary painstaking steps are required to establish their optimal loadings. They impede electron transport and $\mathrm{Li}^{+}$ion pathways resulting in limited sulfur utilization and rate capability. Thus researchers are trying to look for a two-in-one strategy: a bifunctional sulfur host material that combines high conductivity with the ability to chemically bind LiPSs on the surface. The study of $\mathrm{Ti}_{4} \mathrm{O}_{7}$ as a sulfur host material was reported by two groups $[44,45]$. The inherently polar, high surface area metallic oxide cathode host combines electronic conductivity for redox electron transfer with a polar surface for strong $\mathrm{LiPSs} / \mathrm{Li}_{2} \mathrm{~S}$ binding, enabling low capacity fade rates to be sustained. The findings can be generalized to other kinds of Magnéli-phase metal oxides $\left(\mathrm{V}_{\mathrm{n}} \mathrm{O}_{2 \mathrm{n}-1}\right.$, $\mathrm{W}_{\mathrm{n}} \mathrm{O}_{2 \mathrm{n}-1}, \mathrm{Mo}_{\mathrm{n}} \mathrm{O}_{2 \mathrm{n}-1}$, etc.) and some other matrix materials with abundant low coordinated metal sites on surface (Figure 14). 
a

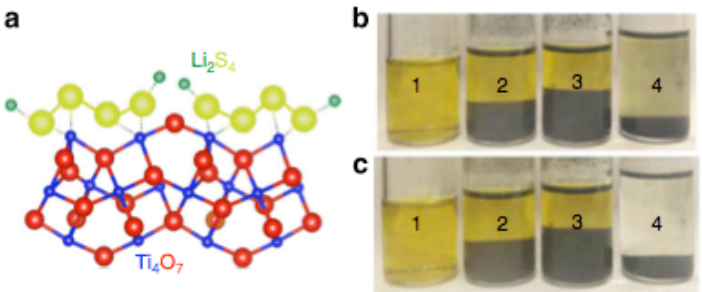

d

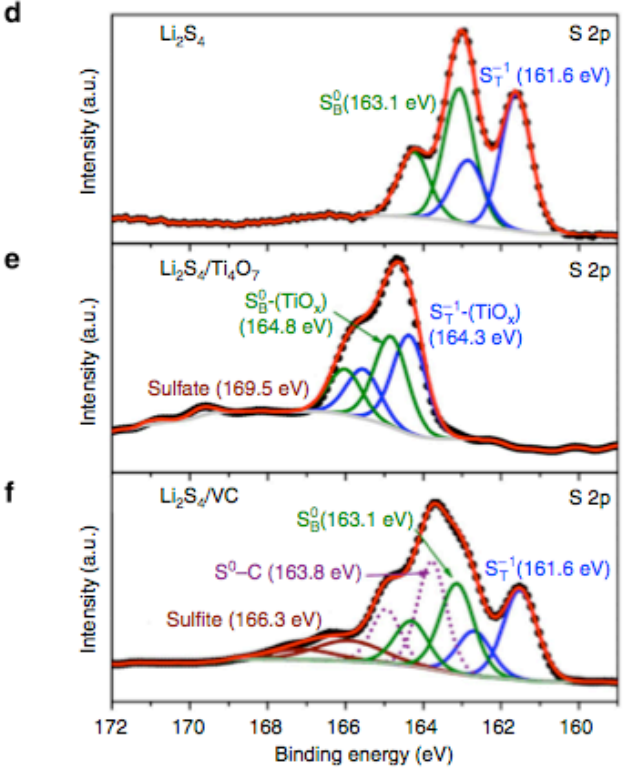

Figure 14. Demonstration of the strong interaction of LiPS with $\mathrm{Ti}_{4} \mathrm{O}_{7}$. (a) A schematic showing the electron density transfer between $\mathrm{Li}_{2} \mathrm{~S}_{4}$ and $\mathrm{TiO}_{x}$ (yellow $1 / 4 \mathrm{~S}$, green $1 / 4 \mathrm{Li}$, blue $1 / 4 \mathrm{Ti}$, red $1 / 4 \mathrm{O})$. (b,c) Sealed vials of a $\mathrm{Li}_{2} \mathrm{~S}_{4} / \mathrm{THF}$ solution (1), and after contact with graphite (2), VC carbon (3) and $\mathrm{Ti}_{4} \mathrm{O}_{7}(4)$, immediately upon contact (b) and after $1 \mathrm{~h}$ stirring (c). (d-f) Highresolution XPS S 2p spectra of (d) $\mathrm{Li}_{2} \mathrm{~S}_{4}$, (e) $\mathrm{Li}_{2} \mathrm{~S}_{4} / \mathrm{Ti}_{4} \mathrm{O}_{7}$ and (f) $\mathrm{Li}_{2} \mathrm{~S}_{4} / \mathrm{VC}$ (black dotted line 1/4 experimental data, red line $1 / 4$ overall fitted data, solid/dotted lines in other colours $1 / 4$ fitted individual components). Reprinted with permission from [44]. Copyrights 2014 Macmillan Publishers Ltd.

An alternative method to sequester sulfur during cycling with high conductive matrix is to apply graphene oxide (GO) [95-98]. Zhang et al. [96] used a chemical reactiondeposition strategy to immobilize Sulfur on quasi-two-dimensional GO to prepare graphene oxide-sulfur (GO-S) nanocomposite cathodes for Li-S batteries. This approach obtained a uniform and thin sulfur coating on GO sheets and enabled the strong interaction between graphene oxide and sulfur or polysulfides, leading to a reversible capacity of $950-1400 \mathrm{mAh} / \mathrm{g}$ and stable cycling for more than 50 deep cycles at $0.1 \mathrm{C}$. A detailed study of the electronic structure and chemical bonding between GO and $\mathrm{S}$ by Xray Photoelectron Spectroscopy (XPS), Near-edge X-ray Absorption Fine Structure (NEXAFS) and X-ray Emission Spectroscopy (XES) was done to better understand the property of this nanocomposite [47]. They found the incorporation of Sulfur can partially reduce the GO and thus improve the conductivity of the GO. The existence of both C-S and O-S bonds was confirmed by the XPS and NEXAFS results. Also, the mild interaction between $\mathrm{GO}$ and $\mathrm{S}$ can not only preserve the fundamental electronic 


\section{III.3 Sequestering sulfur in the cathode using a combination of chemical and physical interactions}

To overcome characteristically low capacity and quick fading, a combination of physical traps and chemical bonds are introduced to suppress shuttling and improve performance. While physical trapping often employs high surface area conductive carbon, the gains in performance are short lived. Similarly, the introduction of favorable chemical bonds is an effective method to sequester PS but low utilization of the active material is often achieved. As such, previous methods that utilize metal oxide frameworks are limited because the insulating nature of the functional groups limits full capacity utilization. To combine these two methods effectively the framework must be conductive. Therefore, a variety of multifunctional nanomaterials are applied to serve both as the physical barrier and thermal adsorbents.

Recent findings have demonstrated heteroatom-doped carbon as a feasible method to combine high surface area carbon matrices and the polar surface for Li-S cells [100-103]. Among various dopants (phosphorus, sulfur, boron, nitrogen), nitrogen is most attractive for substantially improving the carbon surface polar, wettability, and conductivity. The first work of applying N-doped carbon to Li-S battery was reported by Sun et al. [101]. The electrochemical impedance spectroscopy results showed that the charge-transfer resistance in nitrogen-doped carbon cathode was much lower than that of activated carbon without doping. They concluded that nitrogen-doping could enhance activity towards sulfur reduction, providing higher discharge potential and initial capacity. However, surface doping by high temperature treatment limited the doping content to 3.3 $\mathrm{wt} \%$. In contrast, a homogeneous incorporation of nitrogen into the carbon was realized by a controlled chemistry through in situ doping of carbons using nitrogen containing precursors, reported by Ling et al. [100]. The results show that the nitrogen doping could assist mesoporous carbon to suppress the shuttling phenomenon, via an enhanced surface 
interaction between the nitrogen functionalities and polysulfide species. It is also shown that nitrogen doping can improve the electronic conductivity of the carbon matrix within an appropriate content range (4-8 $\mathrm{wt} \%$ ), offering faster charge-transfer kinetics. The cathode composite delivers a high discharge capacity of $758 \mathrm{mAh} / \mathrm{g}$ at $0.2 \mathrm{C}$ and 620 $\mathrm{mAh} / \mathrm{g}$ at $1 \mathrm{C}$ rate after 100 cycles. A more recent work reported by Chen [102], designed and synthesized a novel N-doped carbon-sulfur (NCMSs-S) composite by confining sulfur in porous NCMSs. The S-immobilized NCMs showed very slow decay at $2.0 \mathrm{C}$ $(0.030 \%$ per cycle for 500 cycles) with a reversible capacity of $\sim 605 \mathrm{mAh} / \mathrm{g}$. The authors contributed the results to the confinement of sulfur by porous structure and the ability of the electron-donating atoms $(\mathrm{N}$ and $\mathrm{O}$ ) to absorb the polysulfide produced during the electrochemical reaction. These results would shed light on developing more novel $\mathrm{N}$ - or other elements-doped carbon spheres with suitable porous structures for an ideal sulfurhosted matrix. A detailed study of the effect of carbon-heteroatom bonds in Li-S cells was carried out by Li et al. (Figure 15)[104]. Carbon black substrates were prepared by various treatments to introduce nitrogen or oxygen surface species. The XPS study revealed that the defect sites of nitrogen-doped carbon are favorable for the discharge product deposition, leading to a high utilization and reversibility of sulfur cathodes. For oxygen functional groups, they found negative effect on the sulfur cathode due to the reduced conductivity and unwanted side reactions occurring between sulfur and surface oxygen species. This study indicated the important correlation existing between carbonheteroatom bonds and battery performance.

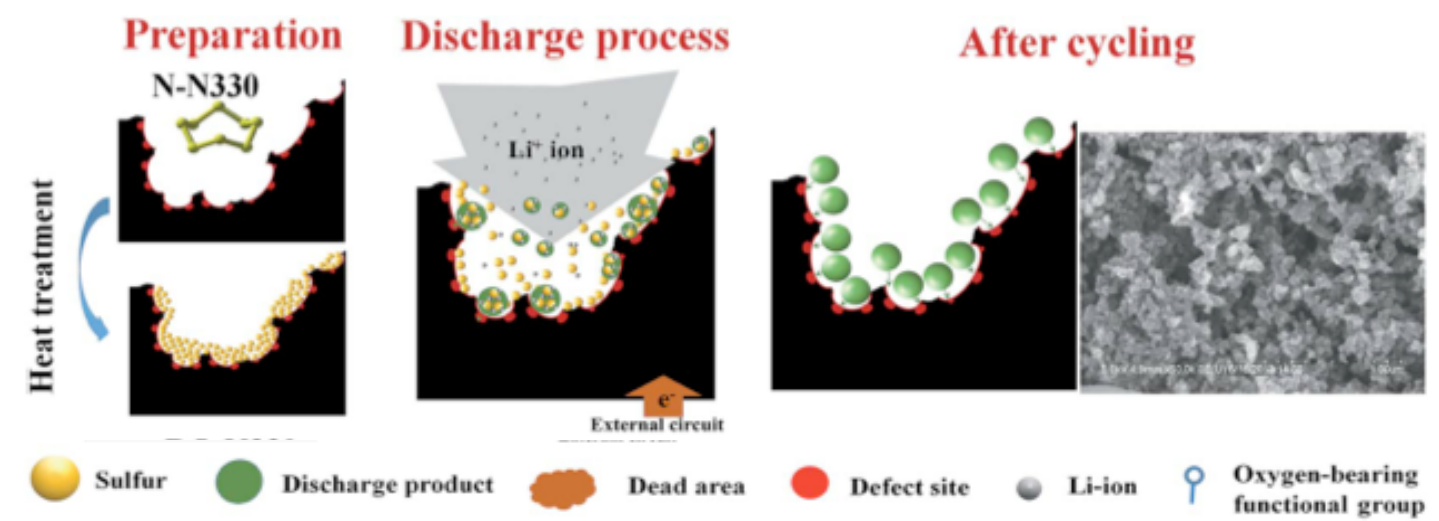

Figure 15. Schematic diagram showing effects of carbon-heteroatom bonds on sulfur cathodes. Reprinted with permission from[104]. Copyrights 2014 The Royal Society of Chemistry.

One method to increase the sulfur loading is to uniformly distribute a thin-layer of sulfur in conductive materials through the strong interaction between $\mathrm{S}$ and conductive host. Transition metals (e.g. $\mathrm{Co}, \mathrm{Ni}$, and $\mathrm{Cu}$, etc.) have been shown to react with sulfur to form sulfides at moderate temperatures, and these sulfides have been investigated as cathode materials for lithium batteries. Researchers are also applying the transition metals to Li-S systems, taking advantage of conductive transition metal-sulfur species [56, 105-107]. Wang [106] reported a design of copper-stabilized sulfur-microporous carbon ( $\mathrm{MC}-\mathrm{Cu}-\mathrm{S}$ ) composite with S loading of $50 \%$ as sulfur cathode by_an ultrasonic-assisted multiple wetness impregnation and synchro-dry technique (Figure 16). The unique structural MC$\mathrm{Cu}-\mathrm{S}$ composite cathode shows Coulombic efficiency close to $100 \%(1.0 \mathrm{M} \mathrm{LiPF} 6+$ 
$\mathrm{EC} / \mathrm{DEC}(1: 1 \mathrm{v} / \mathrm{v}))$, and maintains capacities of around $630 \mathrm{mAh} / \mathrm{g}$ at the current density of $100 \mathrm{~mA} / \mathrm{g}$ with cycling up to 500 cycles. The authors attributed the good performance to the enhanced electronic conductivity of the $\mathrm{MC}-\mathrm{Cu}-\mathrm{S}$ cathodes and the formation of solid $\mathrm{Cu}$-polysulfide clusters through strong interaction between $\mathrm{Cu}$ and $\mathrm{S}$. Also, the porous structure carbon matrix provides a physical barrier to sulfur species and free space for volume change of S/LiPS during cycling. A drawback is that the much lower discharge plateau $(\sim 1.2 \mathrm{~V})$ greatly decreases the energy density of the cells, which limits their appeal even when good active materials utilization and satisfactory cycling performance are achieved. Manthiram et al. [107] and Li et al. [56] both reported using 3D Ni foams as either a cathode or a current collector. The Ni foam matrix works as an electron transport network to improve the electrical conductivity of the cathode, as a container to accommodate the active material, and as a cage to retain the polysulfides in the cathode region during the charge/discharge process. Though the authors didn't point out the chemical bonding between $\mathrm{Ni}$ and $\mathrm{S}$, we believe that the interaction also contributed to the good performance of Li-S cells.

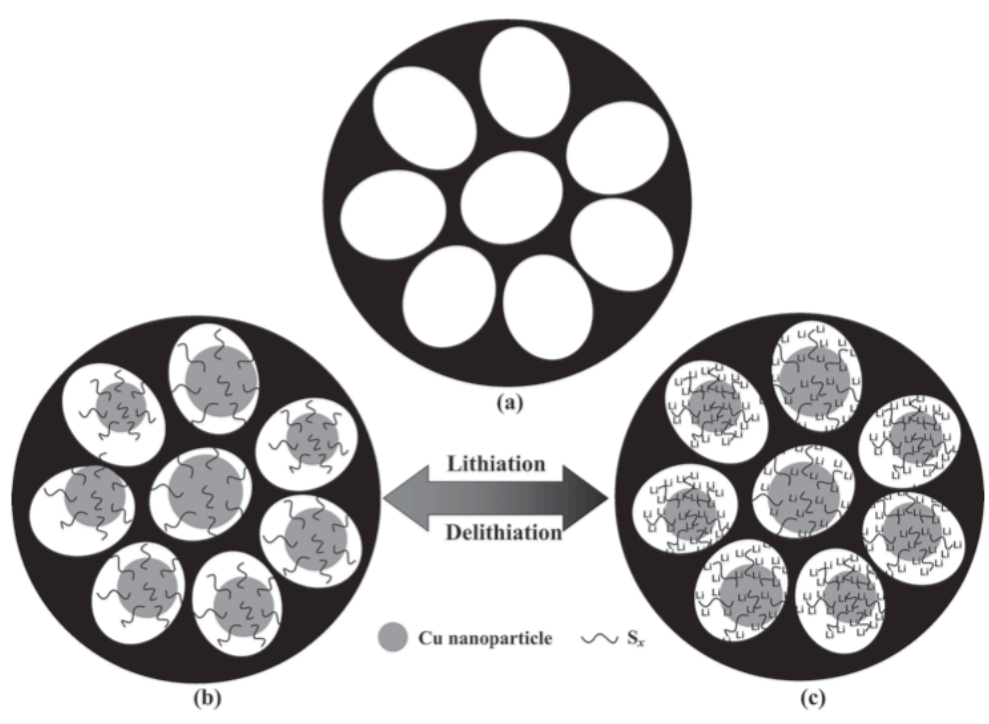

Figure 16. Schematic illustration of lithiation/delithiation process of the $\mathrm{MC}-\mathrm{Cu}-\mathrm{S}$ cathode. Reprinted with permission from [106]. Copyrights 2014 Wiley-VCH Verlag GmbH \& Co. KGaA, Weinheim.

Another method to combine the physical barrier and chemical interaction in Li-S cells is to use metal-organic frameworks (MOFs) [108, 109] [110, 111]. MOFs are attractive for their high porosity and chemical stability. Tarascon et al. [108] first proposed to use mesoporous chromium trimesate MOF, MIL-100 (Cr) as an improved confined matrix for sulfur impregnation. Electrodes containing sulfur impregnated within the pores of the MOF were found to show a marked increase in the capacity retention of Li-S cathodes (Figure 17). The XPS studies demonstrated the reversible capture and release of the polysulfides by the pores of MOF during cycling, and a weak binding between the 
polysulfides and the oxygenated framework was evidenced. However, due to the poor conductivity of the MOFs and sulfur particles, a large amount of carbon is needed to ba added in order to ensure the conductivity of the cathode. Thus Li et al[110] coated the MIL-101 (Cr) with graphene oxide, and the MIL-101 (Cr)@rGO improved the electronic conductivity of meso-MOFs effectively, rising the capacity from $458 \mathrm{mAh} / \mathrm{g}$ of the bare MOFs to $650 \mathrm{mAh} / \mathrm{g}$. A more recent work done by Xiao[109] demonstrated that a novel Ni-based metal organic framework (Ni-MOF) can remarkably immobilize polysulfides within the cathode structure through physical and chemical interactions at the molecular level, and they described the binding as Lewis acid-base interactions, which involves the electron-donating $\mathrm{S}_{\mathrm{x}}{ }^{2-}$ ions and electron-accepting metal ions. The hierarchical porous structure with high surface area of Ni-MOF serves as a sulfur holding matrix to prevent the 'leaking' of soluble species from cathode by physical trapping. More critically, the strong interaction between Lewis acidic Ni (II) center and the polysulfide soft Lewis base successfully trap the soluble species within MOF scaffold, which is confirmed by both theoretical calculations and experimental characterization.

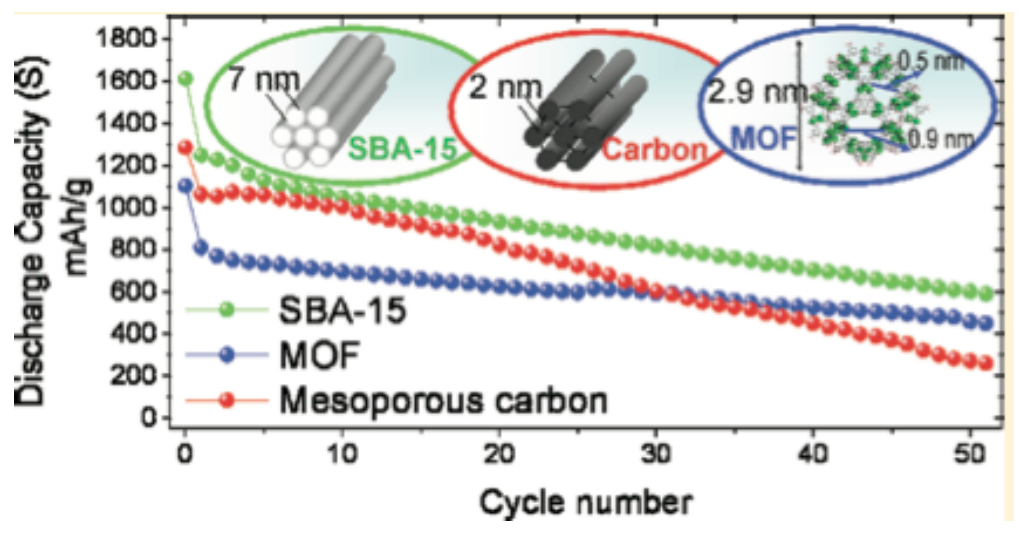

Figure 17. Comparison of battery performance with SBA-15, MOF and Mesoporous carbon. Reprinted permission from [108]. Copyrights 2011 American Chemical Society.

Polymers, especially conductive ones, can be tailored or used to modify the surface of cathodes, facilitating ion and charge transport [112]. In addition, they are soft and selfhealing so that polymer-sulfur composite can accommodate volumetric expansion during discharge [113]. The studies in polymer-sulfur composites have revealed two general approaches that can enhance the electrochemical performance of polymer-sulfur composites. First, the sulfur size should be small in nanometers to achieve homogeneous interaction between sulfur and polymer. The second approach is based on the belief that simple physical confinement on the electrode surface is not sufficient for retarding polysulfide dissolution and thus not effective in achieving a long cycle life. Certain atoms such as $\mathrm{N}, \mathrm{S}, \mathrm{O}$ and some functional groups on the polymer can form stronger chemical bonds towards sulfur such that they can better trap intermediate products and thus superior cycling life[30, 78, 114-117].

Fu et al. [118] have developed a polypyrrole/sulfur composite with the core/shell structure. A cell using this composite as the cathode exhibited a high initial capacity of $1050 \mathrm{mAh} / \mathrm{g}$ and exhibits a high capacity upon 50 cycles at $835 \mathrm{~mA} / \mathrm{g}$. Despite this advantage, it only has $67 \%$ capacity retention after 50 cycles. Similar results can be found 
in other reports with the same-engineered polypyrrole/sulfur composition and structures [114, 118-121]. Xiao et al. [113] have proposed a facile and environmental friendly synthesis process with self-assembling polyaniline nanotubes (PANI-NT) (Figure 18.) for sulfur encapsulation. The polymer treated with sulfur at $280{ }^{\circ} \mathrm{C}$ forms a cross-linked, 3-D and structurally stable polyaniline nanotube-sulfur composite (PANI-NT/S) (shown in Fig). This polymer framework offers strong chemical confinement to sulfur-based components, alleviating the loss of active materials greatly. Additionally, the soft polymer matrix and nanostructured sulfur components have provided cushioning for volume changes during electrochemical reactions. Although relatively low initial discharge capacities occurred at different charge/discharge rates, the electrodes showed a gradual increase in discharge capacities during the initial several tens of cycles, which indicates that SPANI-NT/S composite electrode requires an activation step due to the limited surface area of polyaniline compared to porous carbon. Other polymer/sulfur nanocomposites such as PVP-encapsulated hollow S nanospheres [116], poly(pyrrole-coaniline) (PPyA) copolymer nanofibers[122], core/shell structured polythiophene[30], Sulfur/Poly(acrylonitrile) composite[115], poly(3,4-(ethylenedioxy)thiophene) (PEDOT) /poly(styrenesulfonate) (PSS)-based conductive polymers [117] were also studied extensively by other researchers.

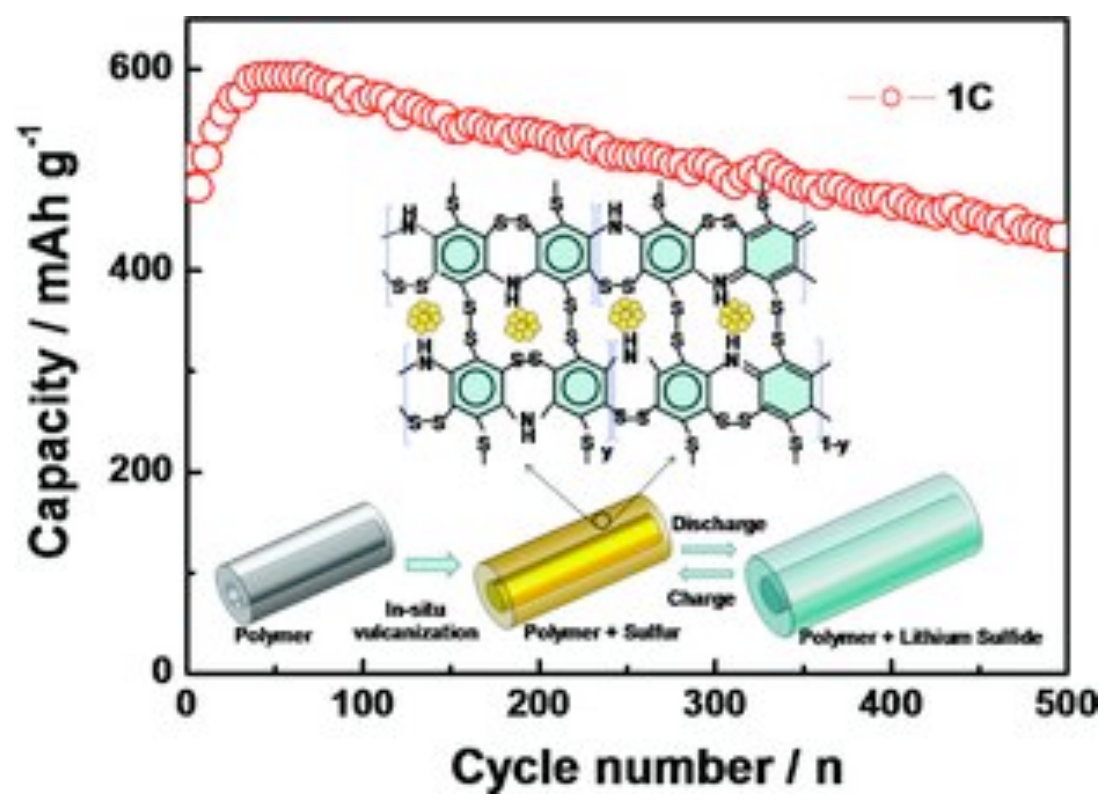

Figure 18. Schematic illustration of the construction and discharge/charge process of the SPANINT/S composite and prolonged cycling performance of the electrode up to 500 cycles at $1 \mathrm{C}$ rate. Reprinted with permission from [113]. Copyrights 2012 Wiley-VCH Verlag GmbH \& Co. KGaA, Weinheim.

\section{Next generation Lithium-Sulfur Batteries}

Although nanostructured cathodes have resulted in considerable improvements in Li-S cells, these improvements typically come at a significant price in terms of the active material content and lost simplicity in manufacturing the cathode. As discussed in the introduction, substantially higher loadings of sulfur in the cathode than typically employed in the majority of current studies are needed to create Li-S batteries that live up to the performance potential of this cell chemistry. Furthermore, despite intensive studies 
by research teams worldwide, capacity fade and shuttling still remain essentially unsolved issues. In pursuit of practical Li-S cells that deliver stable performance, research has recently focused on strategies for designing other components of the cell to improve performance. We expect that explicitly engineered separators and anodes designed to accommodate dissolved LiPS, and at the same time, achieve high levels of active materials utilization will begin to play a significant role in the optimization of these cells. Cleverly designed interlayers can, for example, provide just as efficient structures for constraining LiPS to thin, easily diffusible layers, such that the LiPS can be fully used during discharge. This could ultimately remove the need for high surface area, low density carbon traps now under active study. Furthermore, the results reported in section II suggest that elemental sulfur may be eschewed all together as the cathode in favor of other cell designs the incorporate lower-order LiPS (e.g $\mathrm{Li}_{2} \mathrm{~S}$ or $\mathrm{Li}_{2} \mathrm{~S}_{3}$ ) as the active material in the electrode and/or electrolyte. Use of such a lithiated cathode or catholyte defines a pathway towards alternative anodes such as $\mathrm{Si}, \mathrm{Sn}$, and metal oxides that offer competitive practical energy storage capacities as $\mathrm{Li}$, but avoid its most serious shortcomings.

\section{IV.1 Interlayer and interfacial coatings}

Recently, interlayers have been investigated as a means of improving cycle life and performance of Li-S cells (Figure 19). A bifunctional microporous carbon paper was efficiently used as a cathode interlayer to suppress polysulfide dissolution resulting in an initial discharge capacity of $1367 \mathrm{~mA} \mathrm{~h} \mathrm{~g}^{-1}$ of sulfur at a rate of $1 \mathrm{C} \mathrm{[123].} \mathrm{The} \mathrm{conductive}$ carbon interlayer captures the migrating polysulfides from the cathode during electrochemical reactions while creating good electrolyte penetration for re-utilization of the captured species. Similarly, lithiated graphite can be placed between the anode and separator to function as an anode interlayer [124]. Here the interlayer functions as a solid electrode interface (SEI) by blocking harmful side reactions on the anode to yield stable capacity over $800 \mathrm{~mA} \mathrm{~h} \mathrm{~g}^{-1}$ for 400 cycles at a rate of $1737 \mathrm{~mA} \mathrm{~g}^{-1}$. Since the interlayer acts as a SEI, a closer approximation of this idealized system would constitute the formation of an interfacial coating on the electrode surface. A simple realization of this process is the formation of a protective $\mathrm{LiN}_{3}$ layer on the lithium anode by an in-situ method to suppress the shuttle effect [125]. In one such design, the discharge capacity of the Li-S cell has been reported to remain as high as $773 \mathrm{~mA} \mathrm{~h} \mathrm{~g}^{-1}$ after 500 cycles at a rate of $\mathrm{C} / 2$. The ability of $\mathrm{LiN}_{3}$ to coat the lithium metal produces a stable SEI with fewer reduction species on the anode surface.

Potential benefits of this approach extend beyond the electrode interface as it can also be applied to the separator interface. Recently, it was demonstrated that conductive coatings on the separator can help prevent the aggregation of sulfur at the cathode separator interface [126]. A cell with a pristine polypropylene separator fades to around $400 \mathrm{~mA} \mathrm{~h}$ $\mathrm{g}^{-1}$ within 50 cycles. By using a thin coating of super $\mathrm{P}$ on the separator, an initial discharge capacity of $1350 \mathrm{~mA} \mathrm{~h} \mathrm{~g}^{-1}$ is realized and retains a capacity of 610 after 200 cycles at $\mathrm{C} / 2$. Similarly, layer by layer deposition can be used to coat an ion selective layer onto the separator to inhibit the shuttling effect resulting in a high initial capacity of $1418 \mathrm{~mA} \mathrm{~h}$ g-1 [127]. In such a design, pH-responsive multilayers of weak 
polyelectrolytes were formed using poly(allylamine hydrochloride) (PAH)and poly (acrylic acid) (PAA). It was concluded that the movement of polysulfide anions was significantly inhibited by the presence of five PAH/PAA bilayers. However, although initially high the layer by layer deposition resulted in capacity fade. A more practical method involves coating a fixed layer of Nafion ${ }^{\mathrm{TM}}$ on the separator to create a ion selective membrane with an incredibly low decay rate of $0.08 \%$ per cycle within the first 500 cycles [128]. This results in $\mathrm{SO}_{3}^{-}$group coated channels that allow ion hopping of positive charged species but reject negative ions. As such, polysulfide anions are electrostatically shielded from passage through the separator.

The singular importance of interlayers and interfacial coating is the diversity of these processes. They can be applied on the cathode, anode, and on the separator. This provides three degrees of separation without any advanced or expensive cathode modification. In doing so, Li-S cell can address dissolution separately from PS shuttling. After all, an electrostatic shield or anode coating does not prevent dissolution but instead attacks the complementary challenge of isolating the anode from PS shuttling.

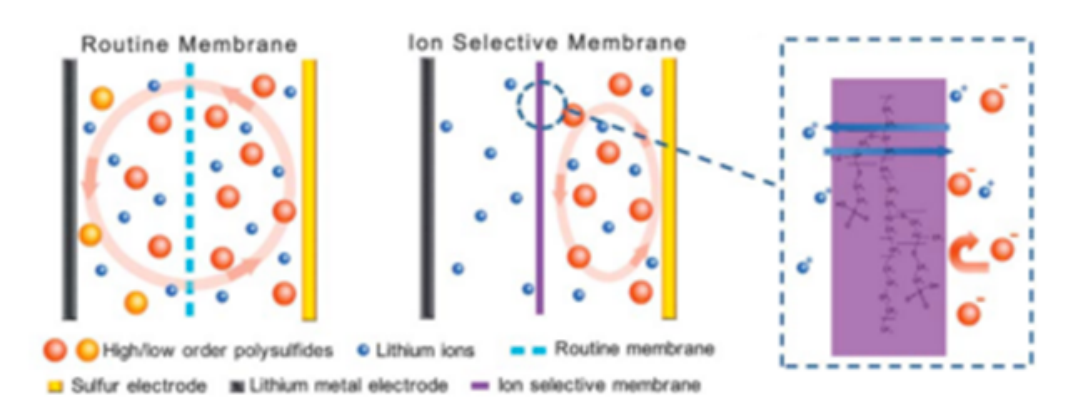

(a)
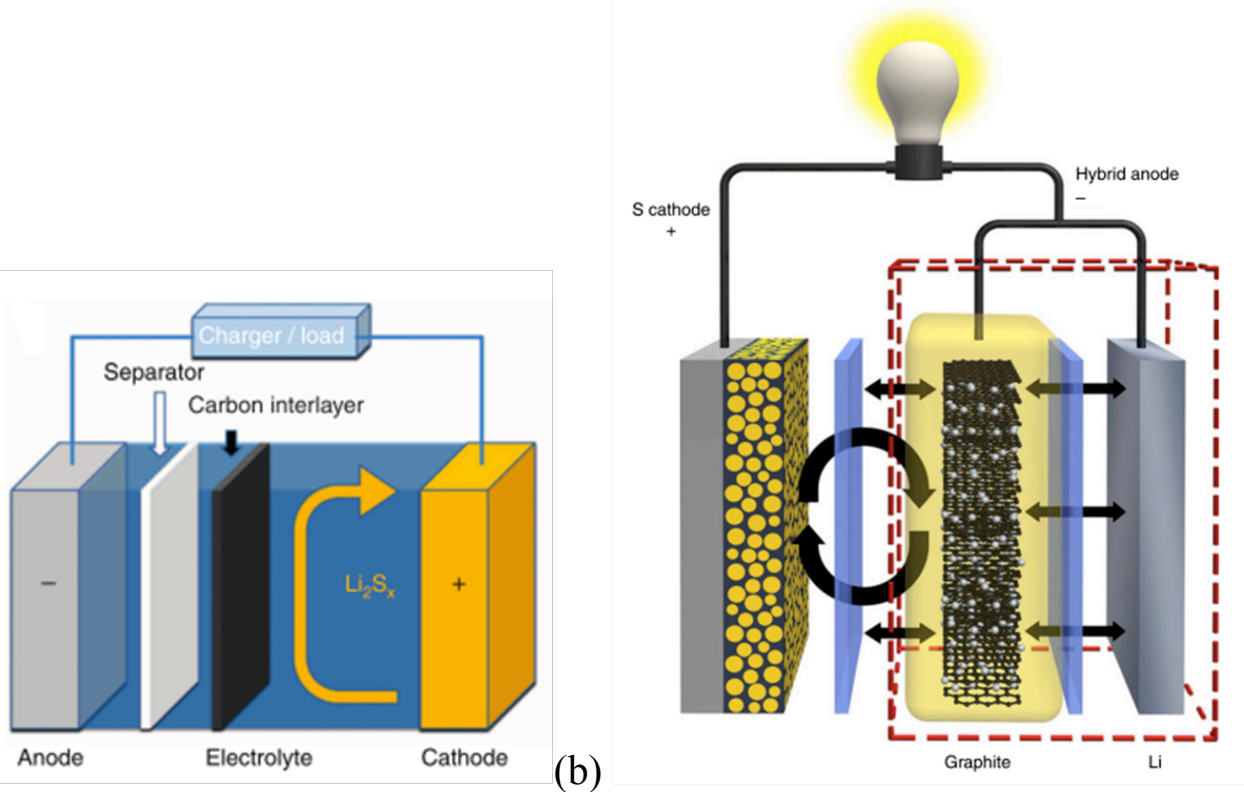

(c)

Figure 19. Illustration of interlayers in Li-S batteries. (a) Schematic of the different lithiumsulfur battery configurations: Cell with routine membranes and cell with ion selective membranes. Enlarged schematic showing that the cation permselective membrane allows the transport of lithium cations and blocks the polysulfide anions. Reprinted with permission from [129]. Copyrights 2014 The Royal Society of Chemistry. (b) Schematic configuration of a Li-S cell 
with a bifunctional microporous carbon interlayer inserted between the sulphur cathode and the separator. Reprinted with permission from [130]. Copyrights 2012 Macmillan Publishers Ltd. (c) Schematic of the hybrid anode design to manipulate the surface reactions on Li-S batteries. Reprinted with permission from [131]. Copyrights 2014 Macmillan Publishers Ltd.

\section{IV.2 Cathodes based on nanostructured $\mathrm{Li}_{2} \mathrm{~S}$}

Incorporating metallic lithium (Li) as the anode in a practical Li-S cell introduces significant challenges that range from higher cell assembly and manufacturing costs associated with reactivity of $\mathrm{Li}$ to atmospheric $\mathrm{O}_{2}$ and moisture to potential safety concerns. Sulfur also undergoes parasitic reaction between with $\mathrm{Li}$ resulting in a considerable volume expansion that results in a safety hazard. The typical need to use an excess of lithium to compensate for losses from side reactions also significantly hamper the volumetric energy density of the Li-S battery.

A Li-S cell in which lithium sulfide $\left(\mathrm{Li}_{2} \mathrm{~S}\right)$ is the cathode material presents as rich opportunities for nanomaterials design as a traditional Li-S cell. Because the cathode is lithiated, it can be used with non-lithiated anodes such as $\mathrm{Si}, \mathrm{Sn}$, metal oxides or graphite. $\mathrm{Li}_{2} \mathrm{~S}$ offers a high specific capacity of $1166 \mathrm{~mA} \mathrm{~h} \mathrm{~g}^{-1}$ that though lower than the theoretical capacity of the Li-S cell, is comparable to what is obtained in the best performing Li-S cells in published reports. Since $\mathrm{Li}_{2} \mathrm{~S}$ is the final discharge product of Li-S battery, its function as a cathode material will follow a similar electrochemical process as sulfur. The inclusion of $\mathrm{Li}_{2} \mathrm{~S}$ provides a new cathode material for lithium metal batteries while simultaneously introducing a new cathode material for LiBs. As such, the incorporation of $\mathrm{Li}_{2} \mathrm{~S}$ as a cathode material results in a safe and compatible Li-free anode. Furthermore, the presence of $\mathrm{Li}_{2} \mathrm{~S}$ reduces volume explanation since $\mathrm{Li}_{2} \mathrm{~S}$ shrinks initially during delithiation generating empty space unlike sulfur which expands $80 \%$ during initial lithiation. However, $\mathrm{Li}_{2} \mathrm{~S}$ suffers from high electronic resistivity and low lithium ion diffusivity which is often a result or the large granular lithium sulfide compounds. Therefore, the incorporation of nanostructured $\mathrm{Li}_{2} \mathrm{~S}$ and nanostrcutured carbon are used to design practical and functional lithium metal and Ion batteries (Figure. 20).

The most common method involves encapsulating $\mathrm{Li}_{2} \mathrm{~S}$ in conductive carbon or high surface area carbon elements. Early work by Yang et. al demonstrated the feasibility of the nanostructured $\mathrm{Li}_{2} \mathrm{~S}$ in a $\mathrm{Li}_{2} \mathrm{~S} / \mathrm{Silicon}$ lithium ion battery [132]. Nanostructured $\mathrm{Li}_{2} \mathrm{~S} /$ carbon composites were generated by combining ordered CMK-3 mesoporous carbon with sulfur, which is then lithiated with n-butyllithium to produce $\mathrm{Li}_{2} \mathrm{~S} / \mathrm{CMK}-3$ composites. It is thought that the lithiation process results in $\mathrm{Li}_{2} \mathrm{~S}$ trapped in 3-4 $\mathrm{nm}$ pores of the mesoporous cathode. The initial discharge capacity of the $\mathrm{Li}_{2} \mathrm{~S} / \mathrm{CMK}-3$ composite of $571 \mathrm{~mA} \mathrm{~h} \mathrm{~g}^{-1}$ of $\mathrm{Li}_{2} \mathrm{~S}$ (contributes $\sim 50 \%$ of the theoretical capacity) represents a significant improvement over commercial microporousLi $\mathrm{i}_{2} \mathrm{~S}$ power. However, such a low theoretical capacity leaves much to be desired if one is to justify the need to replace sulfur as cathode material. As such, further nanostructured device modification is required. A promising realization of this principle is to simply sandwich $\mathrm{Li}_{2} \mathrm{~S}$ between two layers of self-weaving carbon nanotube (CNT) electrodes [133]. By dispersing the insulating $\mathrm{Li}_{2} \mathrm{~S}$ within the electrodes, electronic conduction within two electrodes is optimized to facilitate fast ion transport throughout the CNT nanospace. Furthermore, the 
CNT electrodes used to trap the $\mathrm{Li}_{2} \mathrm{~S}$ particles also act as a trap for charged and discharged products formed upon cycling. The combined effects result in a high initial capacity of 838 and $787 \mathrm{~mA} \mathrm{~h} \mathrm{~g}^{-1}$ of $\mathrm{Li}_{2} \mathrm{~S}$ respectively at $\mathrm{C} / 10$ and $\mathrm{C} / 5$ rates.

An alternative approach is to synthesize nanostructured $\mathrm{Li}_{2} \mathrm{~S}$ as a cathode material. The simplest demonstration of this process is via ethanol solution [134]. The dispersion of commercial $\mathrm{Li}_{2} \mathrm{~S}$ powder in ethanol solution forms nanostructured $\mathrm{Li}_{2} \mathrm{~S}$ nanoparticles. By dispersing PVP in a similar ethanol solution one can combine both mixtures to form a suspension of PVP coated $\mathrm{Li}_{2} \mathrm{~S}$. Such a mixture, after calcination, produces a stable $\mathrm{Li}_{2} \mathrm{~S} /$ carbon complex with a high initial capacity of $1325 \mathrm{~mA} \mathrm{~h} \mathrm{~g}^{-1}$ of sulfur and a stable capacity of $1200 \mathrm{~mA} \mathrm{~h} \mathrm{~g}^{-1}$ of sulfur after 100 cycles at $\mathrm{C} / 5$ [135]. This corresponds to one of the highest capacities observed for $\mathrm{Li}_{2} \mathrm{~S}$ or sulfur cathodes. Since PVP is known to have a strong binding affinity with $\mathrm{Li}_{2} \mathrm{~S}$ by encapsulation $\mathrm{Li}_{2} \mathrm{~S}$ within the PVP coating stable cycle retention is observed. A similar process can be accomplished by encapsulating $\mathrm{Li}_{2} \mathrm{~S}$ in polypyrrole nanoparticles since the nitrogen atoms interact favorably with the lithium in $\mathrm{Li}_{2} \mathrm{~S}$. Using the $\mathrm{Li}_{2} \mathrm{~S}-\mathrm{PPY}$ composite produces a high discharge capacity of $785 \mathrm{~mA} \mathrm{~h} \mathrm{~g}^{-1}$ of $\mathrm{Li}_{2} \mathrm{~S}\left(\sim 1126 \mathrm{~mA} \mathrm{~h} \mathrm{~g}^{-1}\right.$ of sulfur) with stable cycle over 400 cycles at $\mathrm{C} / 5$ [136].

Besides pure $\mathrm{Li}_{2} \mathrm{~S}$ cathodes, hybrid cathodes such as $\mathrm{Li}_{2} \mathrm{~S} /$ metal and $\mathrm{Li}_{2} \mathrm{~S} /$ metal oxide systems have also been investigated. Recently work by Cui and co-workers demonstrated the broad applicability of two-dimensional layered transitional metal disulphides to effectively encapsulate $\mathrm{Li}_{2} \mathrm{~S}$ cathodes [137]. Titanium disulphide $\left(\mathrm{TiS}_{2}\right)$ was used as the encapsulating material to deliver a high specific capacity of $503 \mathrm{~mA} \mathrm{~h} \mathrm{~g}^{-1}$ of $\mathrm{Li}_{2} \mathrm{~S}$ at $4 \mathrm{C}$ with a mass loading of $5.3 \mathrm{mg} \mathrm{cm}$ of $\mathrm{Li}_{2} \mathrm{~S}$. TiS 2 was selected due to its combination of high conductivity and polar Ti-S groups which should facilitate strong interactions with $\mathrm{Li}_{2} \mathrm{~S} / \mathrm{Li}_{2} \mathrm{~S}_{\mathrm{n}}$ species. As such, $\mathrm{Li}_{2} \mathrm{~S} @ \mathrm{TiS}_{2}$ core shell nanostructures were synthesized with over 10 orders of magnitude higher electronic conductivity compared with pure $\mathrm{Li}_{2} \mathrm{~S}$. Furthermore, the general applicability of the results was demonstrated by incorporating both $\mathrm{Li}_{2} \mathrm{~S} @ \mathrm{ZrS}_{2}$ and $\mathrm{Li}_{2} \mathrm{~S} @ \mathrm{VS}_{2}$ as cathode material which obtained initial capacities of 777 and $747 \mathrm{~mA} \mathrm{~h} \mathrm{~g}^{-1}$ of $\mathrm{Li}_{2} \mathrm{~S}$, respectively, at C/5. Impresively,both $\mathrm{Li}_{2} \mathrm{~S} @ \mathrm{ZrS}_{2}$ and $\mathrm{Li}_{2} \mathrm{~S} @ \mathrm{VS}_{2}$ observed a decay rate of $86 \%$ and $87 \%$, respectively, after 100 cycles. Such an impressive result opens the door to new areas of investigation involving utilizing different transition metal disulfides. 
(a)
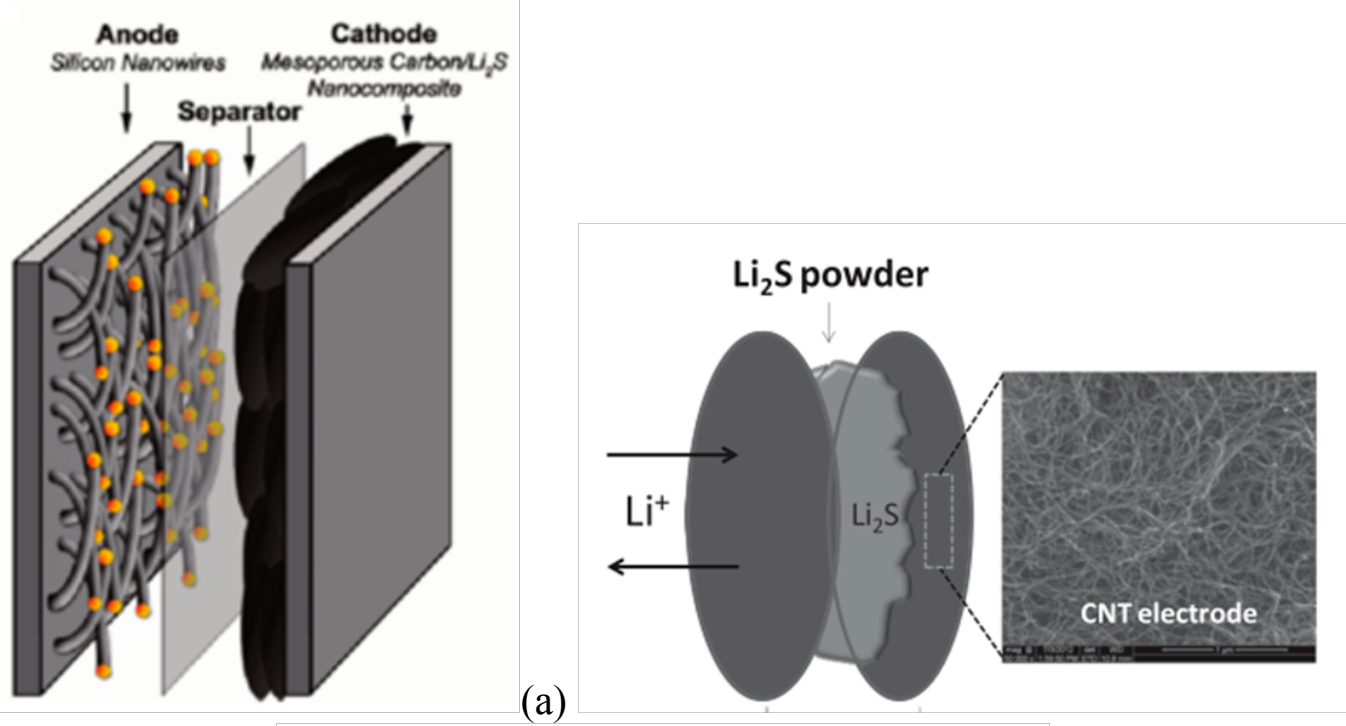

(b)

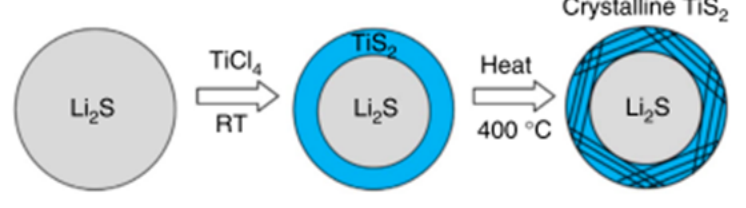

(c)

Figure 20. Illustration of application of $\mathrm{Li}_{2} \mathrm{~S}$ as cathode in Li-S battery. (a) . Schematic of the structure of a $\mathrm{Li}_{2} \mathrm{~S} / \mathrm{Si}$ battery. Reprinted with permission from [132]. Copyrights 2010 American Chemical Society. (b) Schematic showing the structure of a CNT/Li $2 \mathrm{~S} / \mathrm{CNT}$ sandwiched electrode (CNT: carbon nanotube) with a scanning electron microscopy (SEM) image of the CNT electrode. The bold arrows depict the flow of lithium ions during charge and discharge in cells. Reprinted with permission from [133]. Copyrights 2014 Wiley-VCH Verlag GmbH \& Co. KGaA, Weinheim. (c) Synthesis of $\mathrm{Li}_{2} \mathrm{~S} @ \mathrm{TiS}_{2}$ core-shell nanostructures. Reprinted with permission from [137]. Copyrights 2014 Macmillan Publishers Ltd.

\section{IV.3 Li-S cells based on catholytes}

The practically of a $\mathrm{Li}_{2} \mathrm{~S}$ cathode allows one to postulate other lithium sulfide derivatives as future cathode materials. One such example is the dissolved lithium polysulfide system incorporating high order $\mathrm{Li}_{2} \mathrm{~S}_{\mathrm{X}}(3<\mathrm{x}<9)$ in the electrolyte. Such LiPS-based "catholyte" cells have existed for over 30 years. In 1977, the formation of lithium polysulfide $\left(\mathrm{Li}_{2} \mathrm{~S}_{\mathrm{X}}\right)$ by direct in situ reaction of $\mathrm{S}_{8}$ with $\mathrm{Li}$ or $\mathrm{Li}_{2} \mathrm{~S}$ was demonstrated in various apotric media [138]. Two years later in 1979, LiPS was explored as a catholyte in a Li-S battery [139]. The concentration of LiPS in the electrolyte was successfully varied over a wide range, even exceeding 10M. However, the discharge rates were considerably lower than those predicted by the theory and lower concentrations of LiPS resulted in higher capacities compared to higher concentrations of LiPS. This suggests that there is an optimal concentration of the dissolved polysulfide for proper functioning of a high-energy Li-S cell. Early work by Zhang on catholyte-based Li-S cells reported methods to achieve optimal performance $[28,140]$. Specifically, by of LiTFSI and the introduction of $\mathrm{LiNO}_{3}$ in the electrolyte, the author was able to successful design a catholyte cell with capacities 
Recently, LiPS cells using binder-free carbon nanofiber (CNF) paper as the electrode have been reported to reversible yield a capacity of $1094 \mathrm{~mA} \mathrm{~h} \mathrm{~g}^{-1}$ after 80 cycles at $\mathrm{C} / 5$ and at a sulfur loading of $1.7 \mathrm{mg} \mathrm{cm}^{-2}$ [143]. The 3D structure of the CNF paper was argued to facilitate transition between the high order polysulfide and lithium sulfide in a confined environment to produce stable electrochemical performance. Similarly, by combining LiPS as the electrolye in a traditional Li-S battery a stable discharge capacity over $1400 \mathrm{~mA} \mathrm{~h} \mathrm{~g}^{-1}$ was observed over 50 cycles at $\mathrm{C} / 10$. The high concentration of LiPS in the electrolyte prevents further dissolution of Li-PS out of the cathode due to the high concentration gradient inside the electrolyte. The sulfur concentration in the electrolyte was estimated, however, to be only around $1 \mathrm{mg}$. Very recently Hendrickson et al. [144] reported a novel design of a "model" LiPS cell in which the separator is removed and the cell operated in a membrane-free mode. The authors reported that this change results in improvements in both sulfur utilization and cycling performance, whether the sulfur is introduced as a LiPS catholyte or as a composite material in the cathode. The authors rationalized their findings in terms of enhancements in LiPS transport and or reduced loss of LiPS in the separator. These findings open the way for separator designs for Li-S cells, which are engineered at the nanoscale to selectively facilitate transport of the key ionic species, $\mathrm{S}_{6}{ }^{2--} \mathrm{S}_{3}{ }^{2-}, \mathrm{S}_{3}{ }^{-}$, suggested by both theory and XANES experiments. We expect such designs to emerge as a critical component in Li-S battery technologies that achieve high active material utilization and which approach the theoretical capacity for the Li-S cell chemistry.

\section{Conclusion \& Perspective}

The promise of the Li-S battery to store large amounts of electrochemical energy in a low-cost platform has catalyzed enormous activity by researchers world-wide in search of solutions. Based on the accumulated knowledge, from both mechanistic and applicationsoriented studies, there are a good set of design 'rules' that can be used to engineer the sulfur cathode and electrolyte for improved capacity and cycling performance. First, there has to be some sort of conductive additives present in the cathode to ensure electronic access to and full utilization of the active sulfur material. In addition, cathode and electrolyte designs that limit the diffusion of sulfur compounds in the electrolyte are required to maintain high local polysulfide concentrations within the diffusion layer region of the electrode. The most successful approaches should ideally meet both requirements. This review focuses mostly on the role of nanomaterials in the cathode design, however, there is exciting work on electrolyte design, including solid-state 

potentially eliminate polysulfide dissolution, Finally, if unprotected, the metallic lithium anode will continuously react with parasitic reactions with polysulfide species dissolved in the electrolyte, which leads to poor Columbic efficiencies. This means that unless steps are taken to protect the anode, it will ultimately be consumed by these reactions leading to premature cell failure. Addition of $\mathrm{LiNO}_{3}$ as a salt additive in the Li-S battery electrolyte provides a remarkably robust solution to the last of these challenges [147-149]. Although the mechanism responsible for its effectiveness is still under active debate, adding $\mathrm{LiNO}_{3}$ to the Li-S battery electrolyte is practiced by nearly all researchers in the field and the problem of anode degradation via reactions with dissolved LiPS is largely regarded as solved.

The dual challenge of managing low-conductivity and high-solubility active materials in the battery cathode have inspired nanoengineering solutions that provide among the most convincing use of the high surface to volume ratios and short transport lengths that underpin two of the key promises of nanomaterials. Through a steadily rising number of good examples, the review shows that it is now relatively straightforward to find good works in which nanostructures in various form factors and with a variety of mass distributions are used as cathode additives to achieve improved Li-S battery performance, relative to a baseline cell that does not use these additives. Unfortunately, with few exceptions, none of these cells deliver storage capacities greater than $65 \%$ of the theoretical value for the Li-S cell on a gravimetric basis; none deliver a comparable percentage of the theoretical capacity on a volumetric basis. This means the practical capacity of practical Li-S cells derived from these technologies rarely exceed one half of the theoretical capacity of sulfur. This deficiency is significant because it means that despite its theoretical promise, Li-S technology cannot compete with emerging highvoltage lithium ion batteries for high-energy storage in compact portable devices. To retain the advantages inherent in the Li-S battery chemistry, new approaches are needed to lower the content of electrochemically inactive materials in the cathode and at the same time, to engineer Li-S cells that approach the theoretical capacity.

In search of solutions, the review highlights the fundamental and unfavorable effects of chemical and solution equilibria in the cathode and electrolyte in limiting the storage capacity achievable in practical Li-S batteries. In particular it points to the important, if not widely appreciated role, the few theoretical and inoperando studies using the tools of nano-characterication have made in clarifying the fundamental reaction and cell operating mechanisms. In particular, the review points to the large influence intermediate lithium polysulfide species, such as $\mathrm{Li}_{2} \mathrm{~S}_{3}$ - as identified by both theory and in-operando studies may have on overall cell performance. These clues are supported by results from initial experiments reported in Section II and imply that specific strategies for sequestering parent species such as $\mathrm{Li}_{2} \mathrm{~S}_{6}$ that disproportionate to produce $\mathrm{Li}_{2} \mathrm{~S}_{3}$ in the cathode may provide an important step forward. Examples of these approaches are already given in section II, such as controlling the chemical equilibria of LiPS in the electrolyte or controlling the deposition of $\mathrm{Li}_{2} \mathrm{~S}$ on the cathode surface. In an effort to overcome performance barriers associated with the low electrical conductivity of sulfur and sulfides, most published works rely on low mass density, inactive carbon-based conductivity aids. In search of Li-S cells that offer competitive performance on a 
volumetric basis we expect to see increasing use hybrid cathode architectures, in which multiple electrochemically active materials that offer synergistic properties (e.g. $\mathrm{TiS}_{2}$ and $\mathrm{S}_{8}$ ) that do not compromise the volumetric energy density of the cathode are employed.

In conclusion it is clear that research on Li-S cells has lead to clever designs for the cathode and electrolyte that have lead to significant advances in knowledge about how to engineer these components to achieve improvements in cell performance. It is understood, however, that for the Li-S battery to live up to the promise set by its chemistry, additional advances are required to design cells that achieve discharge capacities closer to their theoretical values. The review suggest that advances in this area will require additional understanding and strategies for controlling chemical equilibria between the active species in the electrode and electrolyte. Although the review is silent on the question of electrodeposition and dendrite-induced short circuits normally associated with rechargeable batteries using metallic lithium anodes, it is significant that there have been no literature reports of dendritic shorts in Li-S cells. A straightforward explanation might be that the very same dissolved polysulfide species that can react with the anode and ultimately consume it, may react with and passivate dendrite tips with insoluble, insulative lower order polysulfides, stopping any further growth. This would imply that some amount of deliberately added or dissolved Li-PS generated from reduction of the cathode is required not only for effective utilization of the electrically insulating sulfur at the cathode, but also for safe, dendrite-free operation of a Li-S cell over multiple cycles of charge and discharge. A demonstration of this concept can be found in the works by Hong et al $[150,151]$, which show that dissolved polysulfides facilitate formation of a stable solid electrolyte interphase on the lithium anode.

\section{Acknowledgements}

This publication was based on work supported in part by the National Science Foundation, Partnerships for Innovation Program (Grant\#IIP-1237622); by the Energy Materials Center at Cornell, an Energy Frontier Research Center funded by the U.S. Department of Energy, Office of Science, Office of Basic Energy Sciences under Award Number DE-SC0001086; and by Award No. KUS-C1-018-02, made by King Abdullah University of Science and Technology (KAUST). This work made use of the electron microscopy facility at the Cornell Center for Materials Research (CCMR), an NSF supported MRSEC through Grant DMR-1120296.

\section{References}

[1] P.G. Bruce, S.A. Freunberger, L.J. Hardwick, J.M. Tarascon, Nature materials, 11 (2012) 19-29.

[2] B. Dunn, H. Kamath, J.-M. Tarascon, Science, 334 (2011) 928-935.

[3] J.M. Tarascon, M. Armand, Nature, 414 (2001) 359-367.

[4] C. Jiang, E. Hosono, H. Zhou, Nano Today, 1 (2006) 28-33.

[5] K.T. Lee, J. Cho, Nano Today, 6 (2011) 28-41.

[6] J. Hassoun, B. Scrosati, Advanced materials, 22 (2010) 5198-5201.

[7] Z. Yang, J. Guo, S.K. Das, Y. Yu, Z. Zhou, H.D. Abruña, L.A. Archer, Journal of Materials Chemistry A, 1 (2013) 1433. 
[8] Miller TJ (2009) Electrical Energy Storage for Vehicles: Targets and Metrics, Ford Motor Company

[9] J. Gao, H.D. Abruña, The Journal of Physical Chemistry Letters, 5 (2014) 882-885.

[10] B. Meyer, Chem. Rev., 64 (1964) 429-451.

[11] J.R. Akridge, Y.V. Mikhaylik, N. White, Solid State Ionics, 175 (2004) 243245.

[12] J. Wang, Carbon, 46 (2008) 229-235.

[13] N. Jayaprakash, J. Shen, S.S. Moganty, A. Corona, L.A. Archer, Angewandte Chemie, 50 (2011) 5904-5908.

[14] Q. Zeng, D.-W. Wang, K.-H. Wu, Y. Li, F. Condi de Godoi, I.R. Gentle, Journal of Materials Chemistry A, 2 (2014) 6439.

[15] P.T. Cunningham, S.A. Johnson, E.J. Cairns, J. Electrochem. Soc., 119 (1972) 1448-1450.

[16] J.W. Choi, Electrochim. Acta, 52 (2007) 2075-2082.

[17] G. Zheng, Y. Yang, J.J. Cha, S.S. Hong, Y. Cui, Nano Lett., 11 (2011) 44624467.

[18] Y.-G. Guo, J.-S. Hu, L.-J. Wan, Advanced materials, 20 (2008) 2878-2887.

[19] A. Manthiram, Y. Fu, S.-H. Chung, C. Zu, Y.-S. Su, Chem. Rev., 114 (2014) 11751-11787.

[20] L. Chen, L.L. Shaw, J. Power Sources, 267 (2014) 770-783.

[21] Y.-X. Yin, S. Xin, Y.-G. Guo, L.-J. Wan, Angew. Chem. Int. Ed., 52 (2013) 13186-13200.

[22] Y. Yang, G. Zheng, Y. Cui, Chem. Soc. Rev., 42 (2013) 3018-3032.

[23] D.-W. Wang, Q. Zeng, G. Zhou, L. Yin, F. Li, H.-M. Cheng, I.R. Gentle, G.Q.M. Lu, J. Mater. Chem. A, 1 (2013) 9382-9394.

[24] D. Bresser, S. Passerini, B. Scrosati, Chem. Commun., 49 (2013) 1054510562.

[25] A. Manthiram, Y. Fu, Y.-S. Su, Acc. Chem. Res., 46 (2012) 1125-1134.

[26] S. Evers, L.F. Nazar, Acc. Chem. Res., 46 (2012) 1135-1143.

[27] R.S. Assary, L.A. Curtiss, J.S. Moore, The Journal of Physical Chemistry C, 118 (2014) 11545-11558.

[28] S.S. Zhang, Journal of Power Sources, 231 (2013) 153-162.

[29] R. Elazari, G. Salitra, Y. Talyosef, J. Grinblat, C. Scordilis-Kelley, A. Xiao, J. Affinito, D. Aurbach, Journal of The Electrochemical Society, 157 (2010) A1131.

[30] F. Wu, J. Chen, R. Chen, S. Wu, L. Li, S. Chen, T. Zhao, The Journal of Physical Chemistry C, 115 (2011) 6057-6063.

[31] S.-E. Cheon, K.-S. Ko, J.-H. Cho, S.-W. Kim, E.-Y. Chin, H.-T. Kim, J. Electrochem. Soc., 150 (2003) A796.

[32] H.S. Ryu, Z. Guo, H.J. Ahn, G.B. Cho, H. Liu, Journal of Power Sources, 189 (2009) 1179-1183.

[33] L. Yuan, X. Qiu, L. Chen, W. Zhu, Journal of Power Sources, 189 (2009) 127132.

[34] N.A. Cañas, S. Wolf, N. Wagner, K.A. Friedrich, Journal of Power Sources, 226 (2013) 313-319. 
[35] J. Nelson, S. Misra, Y. Yang, A. Jackson, Y. Liu, H. Wang, H. Dai, J.C. Andrews, Y. Cui, M.F. Toney, Journal of the American Chemical Society, 134 (2012) 63376343.

[36] S. Walus, C. Barchasz, J.F. Colin, J.F. Martin, E. Elkaim, J.C. Lepretre, F. Alloin, Chemical communications, 49 (2013) 7899-7901.

[37] H.-S. Ryu, H.-J. Ahn, K.-W. Kim, J.-H. Ahn, J.-Y. Lee, Journal of Power Sources, 153 (2006) 360-364.

[38] Y. Wang, Y. Huang, W. Wang, C. Huang, Z. Yu, H. Zhang, J. Sun, A. Wang, K. Yuan, Electrochimica Acta, 54 (2009) 4062-4066.

[39] M.A. Lowe, J. Gao, H.D. Abruña, RSC Advances, 4 (2014) 18347.

[40] M.U. Patel, R. Demir-Cakan, M. Morcrette, J.M. Tarascon, M. Gaberscek, R. Dominko, ChemSusChem, 6 (2013) 1177-1181.

[41] M.U. Patel, R. Dominko, ChemSusChem, 7 (2014) 2167-2175.

[42] C. Barchasz, F. Molton, C. Duboc, J.C. Lepretre, S. Patoux, F. Alloin, Analytical chemistry, 84 (2012) 3973-3980.

[43] N.A. Cañas, D.N. Fronczek, N. Wagner, A. Latz, K.A. Friedrich, The Journal of Physical Chemistry C, 118 (2014) 12106-12114.

[44] Q. Pang, D. Kundu, M. Cuisinier, L.F. Nazar, Nature communications, 5 (2014) 4759.

[45] X. Tao, J. Wang, Z. Ying, Q. Cai, G. Zheng, Y. Gan, H. Huang, Y. Xia, C. Liang, W. Zhang, Y. Cui, Nano Lett., 14 (2014) 5288-5294.

[46] R. Demir-Cakan, M. Morcrette, Gangulibabu, A. Guéguen, R. Dedryvère, J.M. Tarascon, Energy \& Environmental Science, 6 (2013) 176.

[47] L. Zhang, L. Ji, P.A. Glans, Y. Zhang, J. Zhu, J. Guo, Phys. Chem. Chem. Phys., 14 (2012) 13670-13675.

[48] J. Guo, Z. Yang, Y. Yu, H.D. Abruna, L.A. Archer, Journal of the American Chemical Society, 135 (2013) 763-767.

[49] L. Ma, H. Zhuang, Y. Lu, S.S. Moganty, R.G. Hennig, L.A. Archer, Advanced Energy Materials, (2014) n/a-n/a.

[50] N.A. Cañas, K. Hirose, B. Pascucci, N. Wagner, K.A. Friedrich, R. Hiesgen, Electrochimica Acta, 97 (2013) 42-51.

[51] M. Cuisinier, P.-E. Cabelguen, S. Evers, G. He, M. Kolbeck, A. Garsuch, T. Bolin, M. Balasubramanian, L.F. Nazar, The Journal of Physical Chemistry Letters, 4 (2013) 3227-3232.

[52] T.A. Pascal, K.H. Wujcik, J. Velasco-Velez, C. Wu, A.A. Teran, M. Kapilashrami, J. Cabana, J. Guo, M. Salmeron, N. Balsara, D. Prendergast, The Journal of Physical Chemistry Letters, 5 (2014) 1547-1551.

[53] M.U. Patel, I. Arcon, G. Aquilanti, L. Stievano, G. Mali, R. Dominko, Chemphyschem : a European journal of chemical physics and physical chemistry, 15 (2014) 894-904.

[54] Z. Li, Y. Jiang, L. Yuan, Z. Yi, C. Wu, Y. Liu, P. Strasser, Y. Huang, ACS Nano, 8 (2014) 9295-9303.

[55] X.-Q. Zhang, Q. Sun, W. Dong, D. Li, A.-H. Lu, J.-Q. Mu, W.-C. Li, J. Mater. Chem. A, 1 (2013) 9449-9455.

[56] X. Tao, X. Chen, Y. Xia, H. Huang, Y. Gan, R. Wu, F. Chen, W. zhang, J. Mater. Chem. A, 1 (2013) 3295-3301. 
[57] L. Ji, M. Rao, S. Aloni, L. Wang, E.J. Cairns, Y. Zhang, Energy Environ. Sci, 4 (2011) 5053-5059.

[58] Y.-J. Choi, Y.-D. Chung, C.-Y. Baek, K.-W. Kim, H.-J. Ahn, J.-H. Ahn, Journal of Power Sources, 184 (2008) 548-552.

[59] S. Xiong, K. Xie, Y. Diao, X. Hong, Ionics, 18 (2012) 867-872.

[60] N.S. Choi, Z. Chen, S.A. Freunberger, X. Ji, Y.K. Sun, K. Amine, G. Yushin, L.F. Nazar, J. Cho, P.G. Bruce, Angewandte Chemie, 51 (2012) 9994-10024.

[61] J. Wang, J. Chen, K. Konstantinov, L. Zhao, S.H. Ng, G.X. Wang, Z.P. Guo, H.K. Liu, Electrochimica Acta, 51 (2006) 4634-4638.

[62] L. Wang, T. Zhang, S. Yang, F. Cheng, J. Liang, J. Chen, Journal of Energy Chemistry, 22 (2013) 72-77.

[63] Y.V. Mikhaylik, J.R. Akridge, Journal of The Electrochemical Society, 151 (2004) A1969.

[64] J.L. Wang, J. Yang, J.Y. Xie, N.X. Xu, Y. Li, Electrochem. Commun., 4 (2002) 499-502.

[65] S. Xin, L. Gu, N.H. Zhao, Y.X. Yin, L.J. Zhou, Y.G. Guo, L.J. Wan, J. Am. Chem. Soc., 134 (2012) 18510-18513.

[66] H. Wang, Y. Yang, Y. Liang, J.T. Robinson, Y. Li, A. Jackson, Y. Cui, H. Dai, Nano Letters, 11 (2011) 2644-2647.

[67] X. Ji, K.T. Lee, L.F. Nazar, Nat. Mater., 8 (2009) 500-506.

[68] Y. Zhao, W. Wu, J. Li, Z. Xu, L. Guan, Adv. Mater., 26 (2014) 5113-5118.

[69] C. Zhang, H.B. Wu, C. Yuan, Z. Guo, X.W. Lou, Angew. Chem. Int. Ed., 51 (2012) 9592-9595.

[70] H.B. Wu, S. Wei, L. Zhang, R. Xu, H.H. Hng, X.W. Lou, Chem. -- A Eur. J, 19 (2013) 10804-10808.

[71] P.G. Bruce, Solid State Ionics, 179 (2008) 752-760.

[72] C. Liang, N.J. Dudney, J.Y. Howe, Chem. Mater., 21 (2009) 4724-4730.

[73] H. Ye, Y.-X. Yin, S. Xin, Y.-G. Guo, J. Mater. Chem. A, 1 (2013) 6602-6608.

[74] B. Zhang, X. Qin, G.R. Li, X.P. Gao, Energy Environ. Sci, 3 (2010) 1531-1537.

[75] S. Moon, Y.H. Jung, W.K. Jung, D.S. Jung, J.W. Choi, D.K. Kim, Adv. Mater., 25 (2013) 6547-6553.

[76] J. Schuster, G. He, B. Mandlmeier, T. Yim, K.T. Lee, T. Bein, L.F. Nazar, Angew. Chem. Int. Ed., 51 (2012) 3591-3595.

[77] X. Li, Y. Cao, W. Qi, L.V. Saraf, J. Xiao, Z. Nie, J. Mietek, J.-G. Zhang, B. Schwenzer, J. Liu, J. Mater. Chem., 21 (2011) 16603-16610.

[78] J. Wang, L. Liu, Z. Ling, J. Yang, C. Wan, C. Jiang, Electrochim. Acta, 48 (2003) 1861-1867.

[79] X. Ji, S. Evers, R. Black, L.F. Nazar, Nat Commun, 2 (2011) 325.

[80] C. Lai, X.P. Gao, B. Zhang, T.Y. Yan, Z. Zhou, J. Phys. Chem. C, 113 (2009) 4712-4716.

[81] G. He, X. Ji, L. Nazar, Energy Environ. Sci, 4 (2011) 2878-2883.

[82] S. Wei, H. Zhang, Y. Huang, W. Wang, Y. Xia, Z. Yu, Energy Environ. Sci, 4 (2011) 736-740.

[83] W. Ahn, K.-B. Kim, K.-N. Jung, K.-H. Shin, C.-S. Jin, J. Power Sources, 202 (2012) 394-399. 
[84] L. Yuan, H. Yuan, X. Qiu, L. Chen, W. Zhu, J. Power Sources, 189 (2009) 1141-1146.

[85] J.-j. Chen, Q. Zhang, Y.-n. Shi, L.-l. Qin, Y. Cao, M.-s. Zheng, Q.-f. Dong, Phys. Chem. Chem. Phys., 14 (2012) 5376-5382.

[86] W. Zheng, Y.W. Liu, X.G. Hu, C.F. Zhang, Electrochim. Acta, 51 (2006) 13301335.

[87] R. Elazari, G. Salitra, A. Garsuch, A. Panchenko, D. Aurbach, Adv. Mater., 23 (2011) 5641-5644.

[88] L.-X. Miao, W.-K. Wang, A.-B. Wang, K.-G. Yuan, Y.-S. Yang, J. Mater. Chem. A, 1 (2013) 11659-11664.

[89] X. Ji, S. Evers, R. Black, L.F. Nazar, Nature communications, 2 (2011) 325.

[90] S. Evers, T. Yim, L.F. Nazar, The Journal of Physical Chemistry C, 116 (2012) 19653-19658.

[91] F. Sun, J. Wang, D. Long, W. Qiao, L. Ling, C. Lv, R. Cai, J. Mater. Chem. A, 1 (2013) 13283.

[92] Y.J. Choi, B.S. Jung, D.J. Lee, J.H. Jeong, K.W. Kim, H.J. Ahn, K.K. Cho, H.B. Gu, Phys. Scr., T129 (2007) 62-65.

[93] A.S. ARICÒ, P. BRUCE, B. SCROSATI, J.-M. TARASCON, W.V. SCHALKWIJK5, Nat. Mater., 4 (2005).

[94] S. Kim, Y. Jung, J.S. Han, J.D. Kim, Google Patents2007.

[95] S. Evers, L.F. Nazar, Chemical communications, 48 (2012) 1233-1235.

[96] L. Ji, M. Rao, H. Zheng, L. Zhang, Y. Li, W. Duan, J. Guo, E.J. Cairns, Y. Zhang, Journal of the American Chemical Society, 133 (2011) 18522-18525.

[97] H. Sun, G.-L. Xu, Y.-F. Xu, S.-G. Sun, X. Zhang, Y. Qiu, S. Yang, Nano Research, 5 (2012) 726-738.

[98] F.-f. Zhang, X.-b. Zhang, Y.-h. Dong, L.-m. Wang, Journal of Materials Chemistry, 22 (2012) 11452.

[99] B. Wang, S.M. Alhassan, S.T. Pantelides, Physical Review Applied, 2 (2014) 034004.

[100] F. Sun, J. Wang, H. Chen, W. Li, W. Qiao, D. Long, L. Ling, ACS applied materials \& interfaces, 5 (2013) 5630-5638.

[101] X.G. Sun, X. Wang, R.T. Mayes, S. Dai, ChemSusChem, 5 (2012) 20792085.

[102] H. Xu, Y. Deng, Z. Zhao, H. Xu, X. Qin, G. Chen, Chemical communications, 50 (2014) 10468-10470.

[103] J. Yang, J. Xie, X. Zhou, Y. Zou, J. Tang, S. Wang, F. Chen, L. Wang, The Journal of Physical Chemistry C, 118 (2014) 1800-1807.

[104] X. Li, X. Li, M.N. Banis, B. Wang, A. Lushington, X. Cui, R. Li, T.-K. Sham, X. Sun, Journal of Materials Chemistry A, 2 (2014) 12866-12872.

[105] J. Hassoun, M. Agostini, A. Latini, S. Panero, Y.-K. Sun, B. Scrosati, Journal of The Electrochemical Society, 159 (2012) A390.

[106] K. Zhang, F. Qin, J. Fang, Q. Li, M. Jia, Y. Lai, Z. Zhang, J. Li, Journal of Solid State Electrochemistry, 18 (2013) 1025-1029.

[107] S. Zheng, F. Yi, Z. Li, Y. Zhu, Y. Xu, C. Luo, J. Yang, C. Wang, Adv. Funct. Mater., 24 (2014) 4156-4163.

[108] S.-H. Chung, A. Manthiram, Electrochimica Acta, 107 (2013) 569-576. 
[109] R. Demir-Cakan, M. Morcrette, F. Nouar, C. Davoisne, T. Devic, D. Gonbeau, R. Dominko, C. Serre, G. Ferey, J.M. Tarascon, Journal of the American Chemical Society, 133 (2011) 16154-16160.

[110] J. Zheng, J. Tian, D. Wu, M. Gu, W. Xu, C. Wang, F. Gao, M.H. Engelhard, J.G. Zhang, J. Liu, J. Xiao, Nano Lett., 14 (2014) 2345-2352.

[111] W. Bao, Z. Zhang, Y. Qu, C. Zhou, X. Wang, J. Li, Journal of Alloys and Compounds, 582 (2014) 334-340.

[112] Z. Wang, X. Li, Y. Cui, Y. Yang, H. Pan, Z. Wang, C. Wu, B. Chen, G. Qian, Crystal Growth \& Design, 13 (2013) 5116-5120.

[113] G. Zheng, Q. Zhang, J.J. Cha, Y. Yang, W. Li, Z.W. Seh, Y. Cui, Nano Lett., 13 (2013) 1265-1270.

[114] L. Xiao, Y. Cao, J. Xiao, B. Schwenzer, M.H. Engelhard, L.V. Saraf, Z. Nie, G.J. Exarhos, J. Liu, Adv. Mater., 24 (2012) 1176-1181.

[115] Y. Fu, A. Manthiram, Chem. Mater., 24 (2012) 3081-3087.

[116] J. Fanous, M. Wegner, J. Grimminger, Ä. Andresen, M.R. Buchmeiser, Chem. Mater., 23 (2011) 5024-5028.

[117] W. Li, G. Zheng, Y. Yang, Z.W. Seh, N. Liu, Y. Cui, Proc. Natl. Acad. Sci. U.S.A, 110 (2013) 7148-7153.

[118] Y. Yang, G. Yu, J.J. Cha, H. Wu, M. Vosgueritchian, Y. Yao, Z. Bao, Y. Cu, ACS Nano, 5 (2011) 9187-9193.

[119] Y. Fu, A. Manthiram, J. Phys. Chem. C, 116 (2012) 8910-8915.

[120] Y. Zhang, Z. Bakenov, Y. Zhao, A. Konarov, T.N.L. Doan, M. Malik, T. Paron, P. Chen, J. Power Sources, 208 (2012) 1-8.

[121] X. Liang, Z. Wen, Y. Liu, H. Zhang, J. Jin, M. Wu, X. Wu, J. Power Sources, 206 (2012) 409-413.

[122] X. Liang, Y. Liu, Z. Wen, L. Huang, X. Wang, H. Zhang, J. Power Sources, 196 (2011) 6951-6955.

[123] L. Qiu, S. Zhang, L. Zhang, M. Sun, W. Wang, Electrochim. Acta, 55 (2010) 4632-4636.

[124] Y.-S. Su, A. Manthiram, Nat Commun, 3 (2012) 1166.

[125] C. Huang, J. Xiao, Y. Shao, J. Zheng, W.D. Bennett, D. Lu, L.V. Saraf, M. Engelhard, L. Ji, J. Zhang, X. Li, G.L. Graff, J. Liu, Nat Commun, 5 (2014).

[126] G. Ma, Z. Wen, M. Wu, C. Shen, Q. Wang, J. Jin, X. Wu, Chem. Commun., 50 (2014) 14209-14212.

[127] H. Yao, K. Yan, W. Li, G. Zheng, D. Kong, Z.W. Seh, V.K. Narasimhan, Z. Liang, Y. Cui, Energy Environ. Sci, 7 (2014) 3381-3390.

[128] M. Gu, J. Lee, Y. Kim, J.S. Kim, B.Y. Jang, K.T. Lee, B.-S. Kim, RSC Adv., 4 (2014) 46940-46946.

[129] J.-Q. Huang, Q. Zhang, H.-J. Peng, X.-Y. Liu, W.-Z. Qian, F. Wei, Energy \& Environmental Science, 7 (2014) 347.

[130] Y.S. Su, A. Manthiram, Nature communications, 3 (2012) 1166.

[131] C. Huang, J. Xiao, Y. Shao, J. Zheng, W.D. Bennett, D. Lu, L.V. Saraf, M. Engelhard, L. Ji, J. Zhang, X. Li, G.L. Graff, J. Liu, Nature communications, 5 (2014) 3015.

[132] Y. Yang, M.T. McDowell, A. Jackson, J.J. Cha, S.S. Hong, Y. Cui, Nano Lett., 10 (2010) 1486-1491. 
[133] Y. Fu, Y.-S. Su, A. Manthiram, Adv. Energy Mater., 4 (2014) n/a-n/a. [134] F. Wu, A. Magasinski, G. Yushin, J. Mater. Chem. A, 2 (2014) 6064-6070. [135] F. Wu, H. Kim, A. Magasinski, J.T. Lee, H.-T. Lin, G. Yushin, Adv. Energy Mater., 4 (2014) n/a-n/a.

[136] Z.W. Seh, H. Wang, P.-C. Hsu, Q. Zhang, W. Li, G. Zheng, H. Yao, Y. Cui, Energy Environ. Sci, 7 (2014) 672-676.

[137] Z.W. Seh, J.H. Yu, W. Li, P.C. Hsu, H. Wang, Y. Sun, H. Yao, Q. Zhang, Y. Cui, Nature communications, 5 (2014) 5017.

[138] R.D. Rauh, K.M. Abraham, G.F. Pearson, J.K. Surprenant, S.B. Brummer, J. Electrochem. Soc., 126 (1979) 523-527.

[139] S.S. Zhang, J.A. Read, J. Power Sources, 200 (2012) 77-82.

[140] Y. Yang, G. Zheng, Y. Cui, Energy Environ. Sci, 6 (2013) 1552-1558.

[141] R. Demir-Cakan, M. Morcrette, Gangulibabu, A. Gueguen, R. Dedryvere, J.M. Tarascon, Energy Environ. Sci, 6 (2013) 176-182.

[142] C. Zu, Y. Fu, A. Manthiram, J. Mater. Chem. A, 1 (2013) 10362-10367.

[143] R. Xu, I. Belharouak, J.C.M. Li, X. Zhang, I. Bloom, J. Bareño, Adv. Energy Mater., 3 (2013) 833-838.

[144] K.E. Hendrickson, L. Ma, G. Cohn, Y. Lu, L.A. Archer, Advanced Science, (2015) n/a-n/a.

[145] Z.L. Z. Lin, N. J. Dudney, C. Liang, ACS Nano, 7 (2013) 2829-2833.

[146] M. Cuisinier, P.E. Cabelguen, B.D. Adams, A. Garsuch, M. Balasubramanian, L.F. Nazar, Energy Environ. Sci, 7 (2014) 2697.

[147] X. Liang, Z. Wen, Y. Liu, M. Wu, J. Jin, H. Zhang, X. Wu, J. Power Sources, 196 (2011) 9839-9843.

[148] S. Xiong, K. Xie, Y. Diao, X. Hong, Electrochim. Acta, 83 (2012) 78-86.

[149] S.S. Zhang, Electrochim. Acta, 70 (2012) 344-348.

[150] S. Xiong, K. Xie, Y. Diao, X. Hong, J. Power Sources, 246 (2014) 840-845.

[151] S. Xiong, K. Xie, Y. Diao, X. Hong, J. Power Sources, 236 (2013) 181-187. 